Review

\title{
Recent strategies to enhance the efficiency of hematite photoanodes in photoelectrochemical water splitting
}

\author{
Dinghua Zhou, Ke Fan * \\ State Key Laboratory of Fine Chemicals, Institute of Artificial Photosynthesis, DUT-KTH Joint Education and Research Centre on Molecular Devices, \\ Institute for Energy Science and Technology, Dalian University of Technology, Dalian 116024, Liaoning, China
}

\section{A R T I C L E I N F O}

\section{Article history:}

Received 8 August 2020

Accepted 21 September 2020

Available online 22 November 2020

\section{Keywords:}

Hematite

Photon absorption efficiency

Charge separation efficiency

Surface injection efficiency

\begin{abstract}
A B S T R A C T
Photoelectrochemical (PEC) water splitting is one of the most promising approaches toward achieving the conversion of solar energy to hydrogen. Hematite is a widely applied photoanode material in PEC water splitting because of its appropriate band structure, non-toxicity, high stability, and low cost. Nevertheless, its relatively low photochemical conversion efficiency limits its application, and enhancing its PEC water splitting efficiency remains a challenge. Consequently, increasing efforts have been rendered toward improving the performance of hematite photoanodes. The entire PEC water splitting efficiency typically includes three parts: the photon absorption efficiency, the separation efficiency of the semiconductor bulk, and the surface injection efficiency. This review briefly discusses the recent advances in studies on hematite photoanodes for water splitting, and through the enhancement of the three above-mentioned efficiencies, the corresponding strategies toward improving the PEC performance of hematite are comprehensively discussed and summarized.
\end{abstract}

(C) 2021, Dalian Institute of Chemical Physics, Chinese Academy of Sciences. Published by Elsevier B.V. All rights reserved.

\section{Introduction}

Developing renewable and environmentally friendly energy sources is critical for addressing energy and environmental issues. Hydrogen is regarded as an attractive alternative to fossil fuels owing to its high calorific value and pollution-free combustion products $[1,2]$. Solar energy-driven water splitting is an ideal technology to obtain green hydrogen as an energy carrier. The main pathways of solar energy conversion into hydrogen via water splitting include the photobiological, photoelectrochemical (PEC), and thermochemical approaches. Among them, PEC water splitting is a prospective approach when compared with the other pathways [3].

The PEC water splitting device comprises two photoelectrodes (a photoanode and a photocathode), an electrolytic cell, an electrolyte, and an external circuit. Therefore, the appropriate selection of photoelectrodes is key toward determining the efficiencies of these devices. In recent years, numerous materials have been employed as photoanodes. Titanium dioxide $\left(\mathrm{TiO}_{2}\right)$ is the earliest explored semiconductor by Fujishima and Honda [4] because of its available energy band position; however, its extremely poor absorbance in the visible spectrum seriously limits its applications. Tungsten trioxide $\left(\mathrm{WO}_{3}\right)$ can absorb part of the visible light with a bandgap of $2.6 \mathrm{eV}$ [5], but the relatively low PEC efficiency and poor stability in alkaline solutions limit its applications. Bismuth vanadate $\left(\mathrm{BiVO}_{4}\right)$ is also a common photoanode material for PEC water splitting [6]. Recent progress has shown that a photocurrent density of 6.1 $\mathrm{mA} \mathrm{cm}{ }^{-2}$ can be attained at $1.23 \mathrm{~V}$ (vs. reversible hydrogen electrode (RHE)), which corresponds to $82 \%$ of the theoretical

\footnotetext{
* Corresponding author. E-mail: kefan@kth.se

This work was supported by the National Natural Science Foundation of China (51772234) and Dalian University of Technology (DUT19RC(3)063). DOI: 10.1016/S1872-2067(20)63712-3 | http://www.sciencedirect.com/science/journal/18722067 | Chin. J. Catal., Vol. 42, No. 6, June 2021
} 
value under illumination [7]. However, poor stability remains a major obstacle in the large-scale application of $\mathrm{BiVO}_{4}$.

Hematite has been attracting considerable attention in PEC water splitting in recent years owing to its advantages, including (1) suitable energy band position, which can supply sufficient driving forces to oxidize water in thermodynamics and a suitable bandgap of approximately $2-2.2 \mathrm{eV}$, which can theoretically absorb $40 \%$ of photons in the solar spectrum; the corresponding theoretical photocurrent density is approximately $12.6 \mathrm{~mA} \mathrm{~cm}-2$, which is significantly superior to that of $\mathrm{BiVO}_{4}$ and $\mathrm{WO}_{3}$; (2) its earth-abundance and cost-effectiveness, as well as (3) excellent stability under a wide $\mathrm{pH}$ range and non-toxicity. However, its relatively low photoelectric conversion efficiency limits its application because of its short hole-diffusion length, poor electrical conductivity, and minority charge mobility, which lead to significant bulk charge recombination $[3,8]$. In addition, its slow oxygen evolution reaction (OER) kinetics, which increases charge recombination and induces a large potential drop at the semiconductor-electrolyte interface (to overcome large overpotential), also limits the efficiency of hematite-based devices.

The entire PEC water oxidation process on photoanodes is composed of three parts (Fig. 1): (1) photoexcitation, wherein the electrons of the valence band (VB) in the semiconductors are excited to the conduction band (CB) by the absorbed photons with sufficient energy, leading to the formation of the photogenerated electrons and holes; (2) charge separation in semiconductors, wherein the photogenerated electrons and holes are separated under the built-in field, and (3) hole injection, wherein the holes that have reached the surface react with water molecules.

Evidently, the incident photon-to-current efficiency (IPCE) of the photoanode semiconductors for water splitting is dependent on the efficiencies of the three processes mentioned above, which can be summarized in the following equation (1):

$$
\operatorname{IPCE}(\lambda)=\eta_{\text {abs }}(\lambda) \times \eta_{\text {sep }} \times \eta_{\text {inj }}
$$

where $\eta_{\mathrm{abs}}(\lambda)$ is the efficiency of photon absorption corresponding to the first process, which is related to wavelength; $\eta_{\text {sep }}$ is the photogenerated carrier separation efficiency, which represents the efficiency of the second process, and $\eta_{\text {inj }}$ is the hole injection efficiency, which describes the efficiency of the

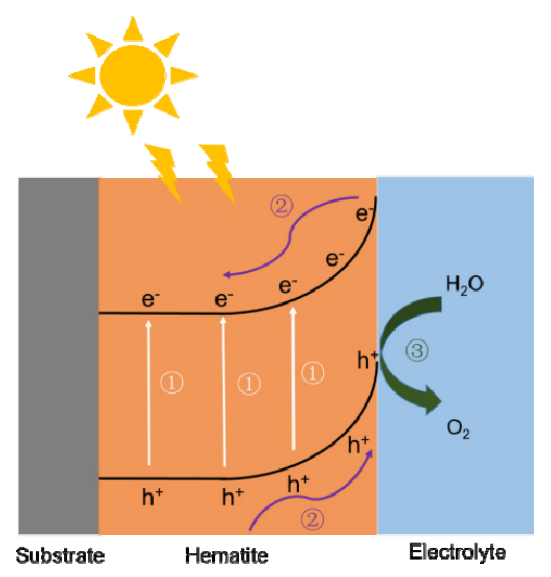

Fig. 1. Schematic of the complete PEC water oxidation process. third process.

Hence, we can improve on the photoelectric conversion efficiency of the entire water splitting device by enhancing the efficiencies of these three processes. Therefore, in this review, we introduce the widely applied strategies (Fig. 2) toward enhancing the PEC performance of hematite-based photoanodes for water splitting.

\section{Strategies to improve the PEC performance of hematite for water splitting}

\subsection{Promotion of the photon absorption efficiency ( $\left.\eta_{\mathrm{abs}}\right)$}

According to the optical absorption theory of solids, only sunlight with a particular wavelength can be absorbed by the semiconductors. In such a case, the energy of the sunlight must satisfy $h v \geqslant E_{\mathrm{g}}$, where $h$ is the Planck constant, $v$ is the frequency of light, and $E_{\mathrm{g}}$ is the bandgap of the semiconductors. For hematite, the light absorption edge is located in the region of 563-652 nm, which is estimated from the known bandgap of 2.2-1.9 eV. The limitation of the light absorption edge, along with the reflection and scattering of the illuminating light by the hematite photoanodes, results in low $\eta_{\text {abs }}$ for water splitting. In recent years, some approaches have been widely adopted to promote the photon absorption efficiency, $\eta_{\text {abs. }}$.

\subsubsection{Building 3D ordered nanophotonic structures}

Some three-dimensional (3D) ordered nanophotonic structures are capable of enhancing the light absorption coefficient of hematite owing to their enlargement of the specific surface area and "trapping" the incident light to the near-surface region [9]. Recently, hierarchical 3D branched hematite nanorod arrays [10] and 3D nanocone hematite arrays $[11,12]$ were synthesized to enhance light harvesting. The scanning electron microscopy (SEM) images of some examples of 3D order nanophotonic structures are shown in Figs. 3(a-c). Qiu et al. studied ultrathin hematite films, which were coated on regular 3D conductive nanospike (NSP) arrays [13]. This structure significantly enhances light absorption compared with the planar hematite electrode, which is evident in the ultraviolet-visible (UV-vis) optical absorption spectra shown in Figs. 3(d-e). Correspondingly, the PEC measurement results also revealed that a Ti-doped hematite electrode with a $1000 \mathrm{~nm}$ pitch exhibited a photocurrent density of $2.42 \mathrm{~mA} \mathrm{~cm}^{-2}$ at $1.23 \mathrm{~V}$ (vs. RHE) in a 1 $\mathrm{M} \mathrm{NaOH}$ solution, which was significantly higher than that of

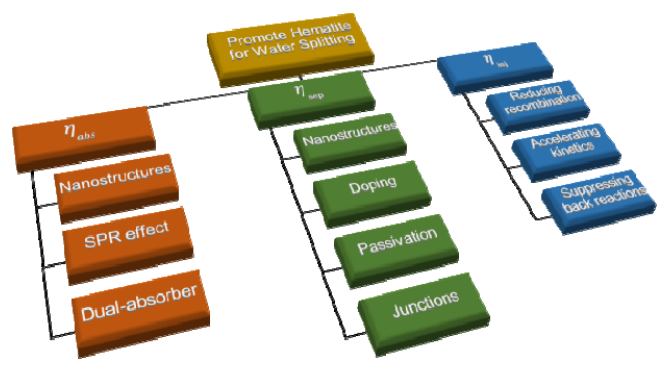

Fig. 2. Main strategies for enhancing PEC performance of hematite for water splitting. 
(a)

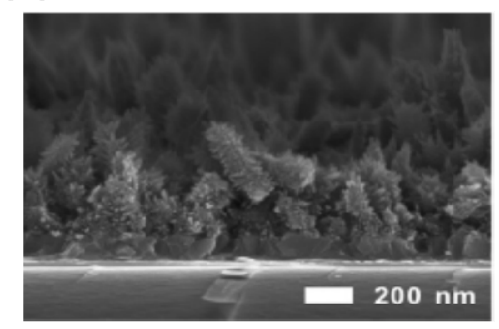

(b)

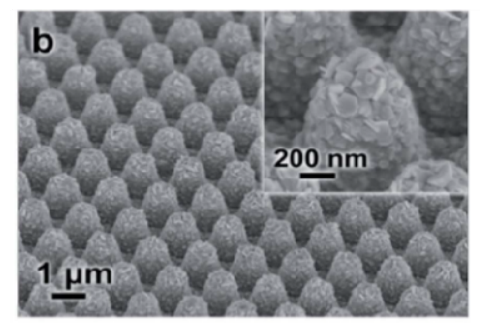

(c)

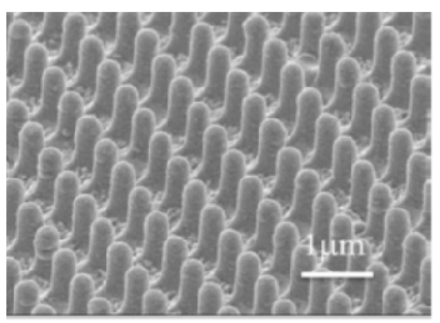

(d)

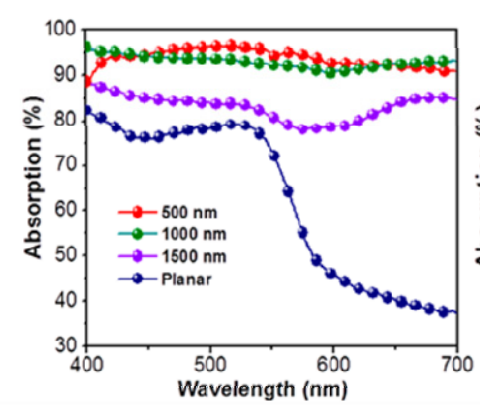

(e)

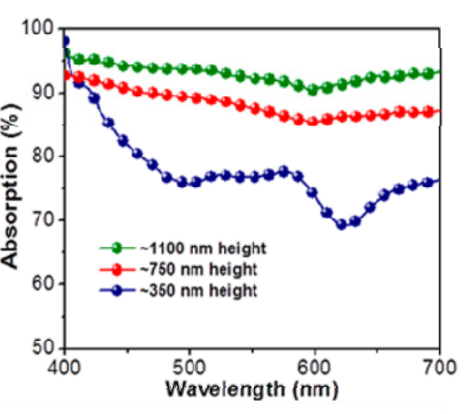

(f)

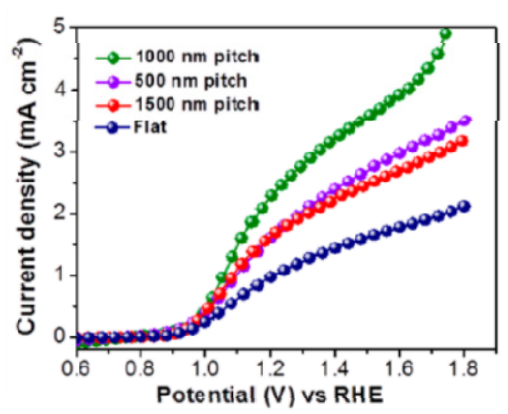

Fig. 3. (a-c) SEM images of some 3D ordered nanophotonic structures of hematite: (a), (b), and (c) adapted with permission from Refs. [10,11], and [13]. Copyright (2016) and (2014) Royal Society of, Chemistry, and (2014) American Chemical Society, respectively. UV-vis optical absorption spectra of the NSP substrate-based device with: (d) different pitches and (e) different heights in a $1000 \mathrm{~nm}$ pitch. (f) J-V curves of the Ti-doped hematite photoelectrodes based on the three different NSP arrays. Adapted with permission from Ref. [13]. Copyright (2014) American Chemical Society.

the flat Ti-doped hematite electrode (Fig. 3(f)).

\subsubsection{Surface plasmon resonance effect}

It is well known that the surface plasmon resonance (SPR) effect is a common strategy to improve semiconductor light harvesting [14-17]. Surface plasmons are bound electromagnetic oscillations of electrons at the interface between a metal and a dielectric material, such as at the interface of a metal and a semiconductor [18]. The plasmonic energy can be transferred from metals to semiconductors to improve the photon absorption efficiency, $\eta_{\text {abs. }}$ Two distinct forms are observed in SPR: (1) surface plasmon polaritons, wherein traveling charge oscillations are resonantly excited on the surface of thin metal films and (2) localized SPR (LSPR), which is the stationary and non-propagating collective oscillation of the surface electrons in metal nanostructures [19]. Notably, Au is usually used as a plasmon metal that can be coupled to semiconductors $[14,16,19,20]$. For example, a hematite-Au hybrid material was synthesized, wherein a hematite nanorod array grew in a plasmonic gold nanohole structure [19]. Compared with the pristine hematite nanorod, the significant enhancement of the absorption efficiency of the hematite-Au electrode is consequent to the LSPR effect.

In addition, Ag [21] and Pd [22] have also been used as plasmon metals coupled with hematite to improve light harvesting. Wang et al. [21] reported a hematite nanosheet electrode that was modified by metal $\mathrm{Ag}$ and CoPi nanoparticles (NPs) (Fig. 4(a)), which exhibited considerably higher IPCE values for water splitting (Fig. 4(c)). Fig. 4(b) illustrates the significant difference in the absorbance between Ag-loaded
$\mathrm{Fe}_{2} \mathrm{O}_{3}$ and $\mathrm{Fe}_{2} \mathrm{O}_{3}$, which is responsible for enhancing the IPCE because Ag plasmons have light scattering properties.

\subsubsection{Dual-absorber systems}

Compositing with another light absorber is also a useful method for promoting photon absorption efficiency. Dual-absorber systems have been used as photocatalysts in the past [23-25]. In recent decades, commonly used photoanodes have been coupled with hematite to construct dual-absorber systems including $\mathrm{BiVO}_{4}, \mathrm{WO}_{3}$, and Si [26-33]. Recently, Zhang et al. [34] prepared an $\mathrm{Fe}_{2} \mathrm{O}_{3}$ nanorod array by means of a solvothermal method; thereafter, they synthesized a hierarchical flower-like nickel ferrite/hematite heterojunction in situ via a facile solution quenching method, which exhibited excellent light absorption properties (extending beyond $850 \mathrm{~nm}$ ) with a bandgap of 1.73-1.88 eV. Müller et al. [35] studied a dual-absorber $\mathrm{Fe}_{2} \mathrm{O}_{3} / \mathrm{WO}_{3}$ system with a higher light absorption, photocurrent density, and earlier onset potential than the pristine $\mathrm{Fe}_{2} \mathrm{O}_{3}$ electrode.

\subsubsection{Other methods}

Doping is another method to modify the photo-absorption region, which is often used in $\mathrm{TiO}_{2}[36,37]$, but has rarely been reported for $\mathrm{Fe}_{2} \mathrm{O}_{3}$. Xie et al. [38] used a fluorine doping strategy to fabricate a hematite electrode. The UV-vis spectrum results show that the main absorption of the spectrum extends from 550-600 $\mathrm{nm}$ after fluorine doping, which is attributed to the generation of defect levels.

To harvest energy photons smaller than the bandgap of hematite, novel plasmonic hematite electrode-coated lantha- 


\section{(a)}
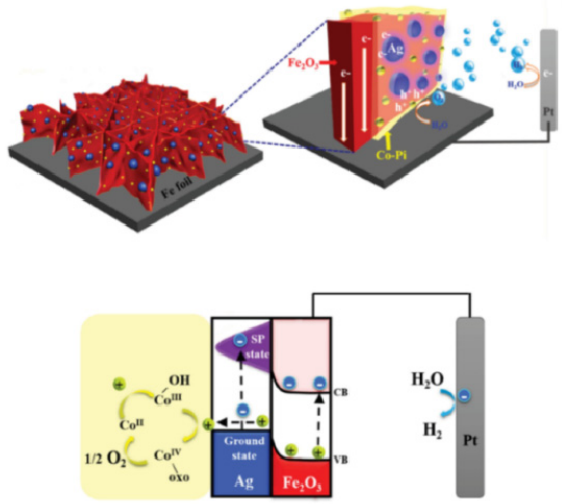

(b)

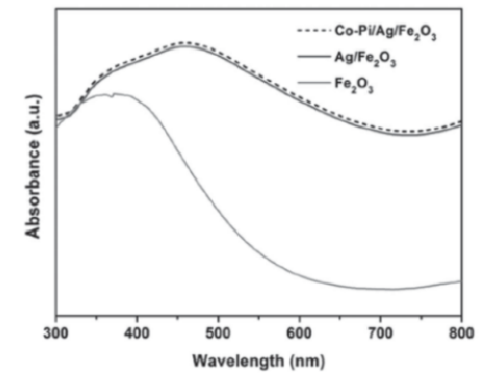

(c)

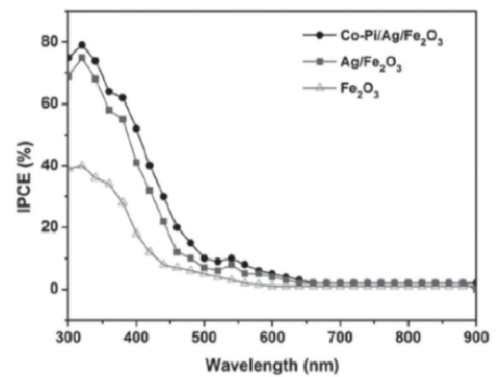

Fig. 4. (a) Schematic of hematite/Ag/CoPi; UV-Vis spectra (b), and IPCE (c) for hematite photoelectrodes. Adapted with permission from Ref. [21]. Copyright (2016) Wiley.

nide upconversion NPs have been reported [39]. Using $\mathrm{NaYF}_{4}$ : $\mathrm{Er}, \mathrm{Yb}$ NPs can upconvert photons from 980 to $510-570 \mathrm{~nm}$, wherein the energy is sufficiently high to surmount the hematite bandgap. This strategy significantly enhances the utilization of photons with less energies than the bandgap of semiconductors.

\subsection{Promotion of the separation efficiency of bulk semiconductors ( $\left.\eta_{\mathrm{sep}}\right)$}

Fig. 5 shows the illuminated situation of the hematite surface (assuming that the direction of the incident light is from the semiconductor-solution (S-S) interface to the semiconductor bulk). Owing to the limited absorption coefficient value, a sufficient hematite layer thickness is essential to achieve an adequate absorption of sunlight. In Fig. 5, L represents the absorption depth. The entire illuminated part of the hematite can be divided into three regions: Region I is the space charge layer of the hematite surface, and $\mathrm{W}$ represents the width of the space charge layer (the normal thickness for hematite is approximately $4-5 \mathrm{~nm}[14,40])$. Furthermore, $\mathrm{L}_{d}$ represents the hole-diffuse length, and region II includes the region in which the width $L_{d}$ is the distance between the space charge layer and the semiconductor bulk. The rest of the illuminated part is region III. According to the Gartner model, only the photogenerated carriers located in the space charge region can be effectively separated by the built-in field, and the carriers in the bulk diffuse to the space charge region, corresponding to regions I and II, thereby contributing to the photocurrents for water splitting $[41,42]$. Herein, we focus on the carrier separation

Table 1

Reports on photon absorption efficiency enhancement.

\begin{tabular}{|c|c|c|c|}
\hline Sample & Electrolyte & Photocurrent density ( $\mathrm{mA} \mathrm{cm}^{-2}$, at $1.23 \mathrm{~V} v \mathrm{vs}$ RHE) & Ref. \\
\hline 3D branched $\mathrm{Fe}_{2} \mathrm{O}_{3}$ nanorod & $1 \mathrm{M} \mathrm{NaOH}$ & 0.61 & [10] \\
\hline 3D nanocone $\mathrm{Ti}-\mathrm{Fe}_{2} \mathrm{O}_{3}$ array & $1 \mathrm{M} \mathrm{NaOH}$ & 2.24 & [11] \\
\hline $3 \mathrm{D} \mathrm{Ti}-\mathrm{Fe}_{2} \mathrm{O}_{3}$ nanospikes & $1 \mathrm{M} \mathrm{NaOH}$ & 2.42 & [13] \\
\hline $\mathrm{Au}-\mathrm{Fe}_{2} \mathrm{O}_{3}$ & $1 \mathrm{M} \mathrm{NaOH}$ & $\sim 1.00$ & [19] \\
\hline $\mathrm{Ag}-\mathrm{Fe}_{2} \mathrm{O}_{3}$ & $1 \mathrm{M} \mathrm{NaOH}$ & 3.20 & [21] \\
\hline $\mathrm{Pd}-\mathrm{Fe}_{2} \mathrm{O}_{3}$ & $0.1 \mathrm{M} \mathrm{Na}_{2} \mathrm{~S}$ and $0.1 \mathrm{M} \mathrm{Na}_{2} \mathrm{SO}_{3}$ & $\mathrm{~N} / \mathrm{A}$ & [22] \\
\hline $\mathrm{BiVO}_{4}-\mathrm{Fe}_{2} \mathrm{O}_{3}$ & $1 \mathrm{M} \mathrm{NaOH}$ & $\sim 0.50$ & [31] \\
\hline $\mathrm{WO}_{3}-\mathrm{Fe}_{2} \mathrm{O}_{3}$ & $0.1 \mathrm{M} \mathrm{NaOH}$ & 0.70 & [35] \\
\hline $\mathrm{WO}_{3}-\mathrm{Fe}_{2} \mathrm{O}_{3}$ & $0.5 \mathrm{M} \mathrm{NaSO}_{4}$ & 1.66 & [29] \\
\hline $\mathrm{Si}-\mathrm{Fe}_{2} \mathrm{O}_{3}$ & $1 \mathrm{M} \mathrm{NaOH}$ & $\sim 0.90$ & [26] \\
\hline F-doped $\mathrm{Fe}_{2} \mathrm{O}_{3}$ & $1 \mathrm{M} \mathrm{KOH}$ & 2.52 & [38] \\
\hline
\end{tabular}




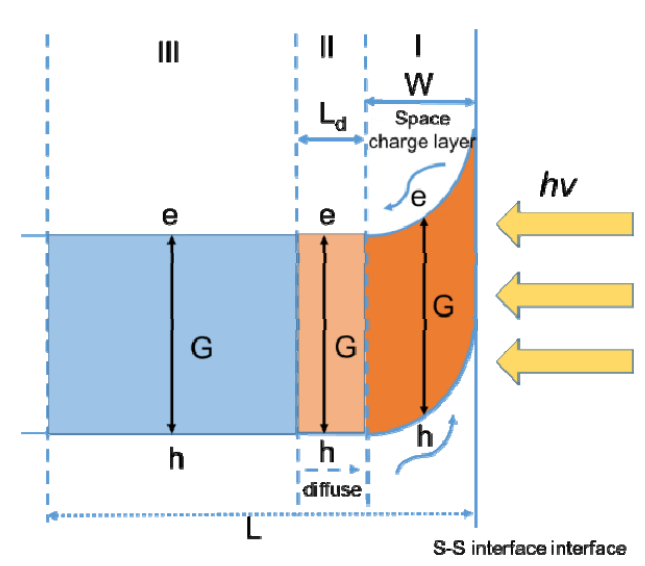

Fig. 5. Illuminated situation of the hematite surface, $G$ represents the generation of electron-hole pairs by photoexcitation.

issues within the space charge layer.

The two time parameters, namely, $\tau_{1}$ and $\tau_{2}$, which represent the recombination reaction time and the carrier (hole or electron) drift time in the charge separation process, respectively, can be simply assumed. From the above-mentioned analysis, it can be predicted that there are two ways to promote the separation efficiency: One way is to increase $\tau_{1}$ (i.e., decrease the recombination rate) through the passivation of the recombination center and/or lower the electron concentration in the space charge region. The concrete strategies to achieve this include decreasing the grain boundaries of the materials and developing the electron depletion. Another way is to decrease $\tau_{2}$ (i.e., the photogenerated carriers are extracted faster), and the main means of accomplishing this entails reducing the carrier migration distance and improving carrier mobility, thereby enhancing the built-in field.

\subsubsection{Nanostructure (decrease $\tau_{2}$ )}

The fabrication of unique nanostructures is considered as an efficient way to shorten the distance from the bulk to the surface of the materials and decrease $\tau_{2}$ (it could be best to trade-off the photon absorption efficiency meanwhile). One-dimensional (1D) materials such as nanowires and nanorods are usually effectively used owing to their dimensions, which are comparable to carrier diffusion lengths [43]. An ultrafine $(\sim 10 \mathrm{~nm})$ hematite nanowire array was fabricated [44]. Figs. 6(a) and 6(c) show the morphological images of the ultrafine hematite nanowires and the PEC performance curves. The PEC measurement results reveal that the ultrafine hematite nanowire photoelectrodes show superior charge separation efficiencies over the nanorod photoelectrodes $\left(\mathrm{Fe}_{2} \mathrm{O}_{3} \mathrm{NRs}\right)$, and the enhancement of the charge separation efficiency is partly attributed to the reduced charge transfer distance owing to the 1D nanowire structure. Luo et al. fabricated a hierarchical branched $\mathrm{Fe}_{2} \mathrm{O}_{3}$ nanorod array $\left(\mathrm{Fe}_{2} \mathrm{O}_{3}\right.$ BNRs) through a two-step hydrothermal method [45]. The morphological images of $\mathrm{Fe}_{2} \mathrm{O}_{3}$ BNRs and PEC performance are illustrated in Figs. 6(b) and 6(e). Notably, higher photocurrents and charge separation efficiencies were obtained for $\mathrm{Fe}_{2} \mathrm{O}_{3}$ BNR photoelectrodes compared to those of the bare $\mathrm{Fe}_{2} \mathrm{O}_{3}$ nanorod $\left(\mathrm{Fe}_{2} \mathrm{O}_{3}\right.$ NRs) photoelectrodes because of the hierarchical structure, which efficiently shortened the drift distance of the holes and decreased $\tau_{2}$.

The nanoporous structure, which is composed of particles whose sizes are approximately close to the semiconductor hole-diffusion length, is believed to be an available structure to enhance the charge separation efficiency of bulk semiconductors. Moreover, it has been widely used in $\mathrm{TiO}_{2}$ and $\mathrm{BiVO}_{4}$ electrodes and has achieved excellent water splitting performances $[46,47]$. In the early years, nanoporous hematite thin films consisting of dozens of nanometer-sized particles were prepared (a)

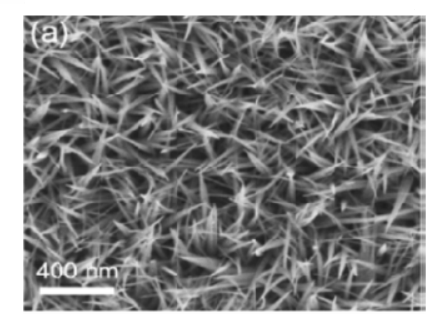

(d)

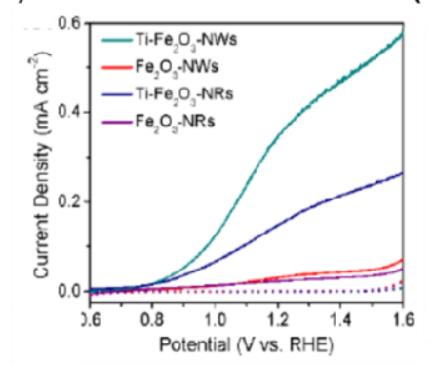

(b)

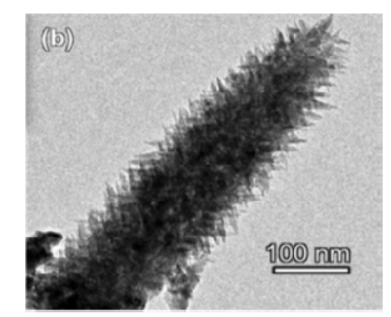

(e)

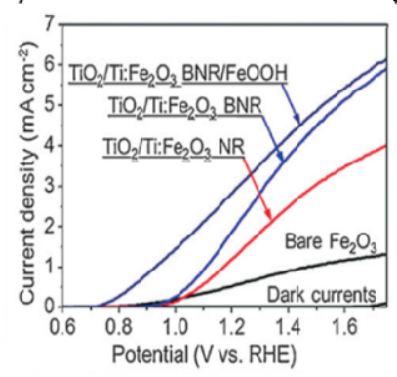

(c)

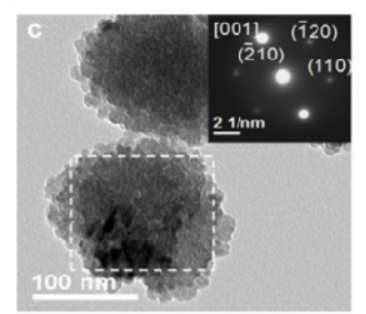

(f)

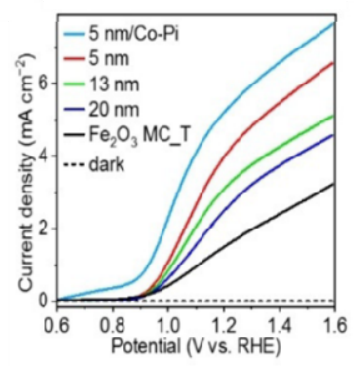

Fig. 6. Morphological images (a-c) and PEC performance curves (d-f) of some special nanostructure hematite electrodes. Adapted with permission from Ref. [44,45,50]. Copyright (2018) American Chemical Society, (2017) and (2020) Wiley. 
$[48,49]$. However, only low photocurrent and IPCE values of water splitting have been obtained because of the bulk or grain boundary recombination of charge carriers. Recently, Zhang et al. fabricated a hematite electrode with mesocrystal superstructures and nanoparticle sizes of approximately $5 \mathrm{~nm}$ [50]; Fig. 6(c) shows the transmission electron microscopy (TEM) image of this device. The nanoparticle size is close to the hole-diffusion length of hematite, which is ideal for suppressing bulk recombination. The authors compared the PEC water splitting performance of different particle-sized Ti-modified $\mathrm{Fe}_{2} \mathrm{O}_{3}$ photoelectrodes and unmodified $\mathrm{Fe}_{2} \mathrm{O}_{3}$ mesocrystal photoelectrodes $\left(\mathrm{Fe}_{2} \mathrm{O}_{3}\right.$ MC_T) (Fig. 6(f)), and the results showed that smaller particle sizes could lead to better performances, which was due to the shorter distance of charge transport to the surface.

\subsubsection{Doping (decrease $\tau_{2}$ )}

Doping hematite with heteroatoms can significantly enhance the carrier mobility and density. Improving the carrier mobility (faster drift velocity in the built-in field) and density (increasing band bending and then enhancing built-in field intensity) can dramatically decrease $\tau_{2}$. The commonly applied method is the N-type doping, such as the replacement of $\mathrm{Fe}^{3+}$ by tetravalent and pentavalent ions, which leads to an increment of the donor density. Notably, the increased carrier density can enhance band bending at the semiconductor/electrolyte interface [51]. For instance, $\mathrm{Ti}^{4+}$ and $\mathrm{Zr}^{4+}$ doping has been usually employed to modify hematite in the past years [52,53]. Additionally, Sn-doped hematite nanowire electrodes were fabricated via the hydrothermal method [54], which generated a photocurrent density of $1.86 \mathrm{~mA} \mathrm{~cm}^{-2}$ at $1.23 \mathrm{~V}$ (vs. RHE) for water splitting, representing a 1.5-times higher value than bare hematite nanowires. The possible reasons for the improved performance include the increase in electrical conductivity derived from Sn element doping. Similar results have also been reported [55], wherein the enhancement of the carrier density is due to Sn-doping in hematite, leading to increased conductivity and reduced bulk recombination. Notably, fluorine-doped tin oxide (FTO) glass is widely used as the substrate and unintentionally causes Sn-doping of hematite in high-temperature calcination. Jang et al. studied the effect of FTO deformation by calcination [56]. When the calcination temperature reaches 800 ${ }^{\circ} \mathrm{C}, \mathrm{Sn}^{4+}$ from FTO diffuses into the hematite lattice and induces the doping effect.

In addition to metal ions, doping with nonmetal ions also enhances the charge separation efficiency. Commonly, a P-doped hematite electrode has been fabricated via impregnation and hydrothermal methods [57]. A photocurrent density of $2.7 \mathrm{~mA} \mathrm{~cm}^{-2}$ at $1.23 \mathrm{~V}$ (vs. RHE) for water splitting was obtained for the P-doped hematite, which was significantly superior to that of bare hematite $(0.83 \mathrm{~mA} \mathrm{~cm}-2)$. Furthermore, the P-doping of hematite improves electron mobility. Evidently, this homogeneous doping can improve donor concentration; however, it can also narrow the space charge region, which is unfavorable for charge separation. To overcome this issue, Luo et al. [51] prepared a gradient P-doped hematite nanoarray photoanode, which showed superior PEC water oxidation per- formance. The authors found that a short thermal treatment time $\left(750{ }^{\circ} \mathrm{C}, 10 \mathrm{~min}\right)$ for hematite after soaking in phosphate could induce the incorporation of gradient $\mathrm{P}$. This could be because of the diffusion of $\mathrm{P}$ in the thermal treatment from the surface to the hematite core. The driving force of diffusion is the $\mathrm{P}$ concentration difference between the surface and the bulk. Once the thermal treatment is stopped, the diffusion rate of $\mathrm{P}$ becomes slow; hence, a gradient P-doped hematite nanoarray photoanode can be obtained. However, if the thermal treatment time further increases $\left(750{ }^{\circ} \mathrm{C}, 30 \mathrm{~min}\right)$, the concentration gradient of $\mathrm{P}$ will diminish and tend to form homogeneous doping. In Fig. 7(a), the measurement results of the PEC water oxidation activity for bare $\mathrm{Fe}_{2} \mathrm{O}_{3}$, homogeneous P-incorporated $\mathrm{Fe}_{2} \mathrm{O}_{3}$ (homo- $\mathrm{P}: \mathrm{Fe}_{2} \mathrm{O}_{3}$ ), gradient P-incorporated $\mathrm{Fe}_{2} \mathrm{O}_{3}$ (grad-P: $\mathrm{Fe}_{2} \mathrm{O}_{3}$ ), depositing a $\mathrm{CoPi}$ cocatalyst on homo-P: $\mathrm{Fe}_{2} \mathrm{O}_{3}$ (homo-P: $\mathrm{Fe}_{2} \mathrm{O}_{3} / \mathrm{CoPi}$ ), and depositing a Co-Pi cocatalyst on grad-P: $\mathrm{Fe}_{2} \mathrm{O}_{3}$ (grad-P: $\mathrm{Fe}_{2} \mathrm{O}_{3} / \mathrm{CoPi}$ ) photoanodes are shown. It is evident that the order of the overall $\mathrm{PEC}$ performance is grad-P: $\mathrm{Fe}_{2} \mathrm{O}_{3}>$ homo-P: $\mathrm{Fe}_{2} \mathrm{O}_{3}>$ bare $\mathrm{Fe}_{2} \mathrm{O}_{3}$. Meanwhile, Fig. 7 (b) displays the charge separation efficiency of all the electrodes. The efficiency of grad-P: $\mathrm{Fe}_{2} \mathrm{O}_{3}$ is superior to that of homo-P: $\mathrm{Fe}_{2} \mathrm{O}_{3}$. A possible explanation can be inferred from Figs. 7(c-f). Traditional homogeneous P-doping induces carrier density enhancement, as well as causes an increase in band bending (Fig. 7(c)), which is conducive to improving the separation efficiency. However, when the concentration of doping further increases (Figs. 7(d,e)), the excessive carrier density narrows the space charge layer of the semiconductors. Alternatively, the authors used the gradient-doping method. In contrast to homogeneous doping, the gradient distribution of $\mathrm{P}$ induces enhanced band bending from the hematite core to the surface, which widens the total space charge region and further enhances the separation efficiency (Fig. 7(f)).

Apart from single-element doping, dual-element doping is often used to modify hematite photoanodes as well. Notably, Ti and $\mathrm{Mg}$ co-doping hematite electrodes for water splitting were used recently [58]. Compared with single-element $\mathrm{Ti}$ or $\mathrm{Mg}$ doping, Ti and Mg co-doped hematite electrodes have a higher separation efficiency, which is ascribed to the polar hopping effect. Liu et al. [59] fabricated a dual-axial gradient-doping hematite nanorod, including $\mathrm{Zr}$ doping in the X-axial and Sn doping in the Y-axial directions, and they obtained a superior charge separation efficiency. The enhancement of the efficiency for dual-axial gradient-doping is probably because the $\mathrm{Zr}$ gradient-doping in the X-axial direction increases band bending over a large region. However, the Sn gradient-doping in the Y-axial direction could decrease the surface trapping states, thereby accelerating charge separation and decreasing the surface recombination.

\subsubsection{Junction (increase $\tau_{1}$, decrease $\tau_{2}$ )}

Building a junction with hematite is an effective path toward promoting charge separation in the semiconductor bulk. The junction could be a metal-semiconductor (Schottky) junction or a semiconductor-semiconductor (S-S) junction. The junction induces or enhances the built-in field and deepens electron (hole) depletion for the material formatted junction with hem- 
(a)

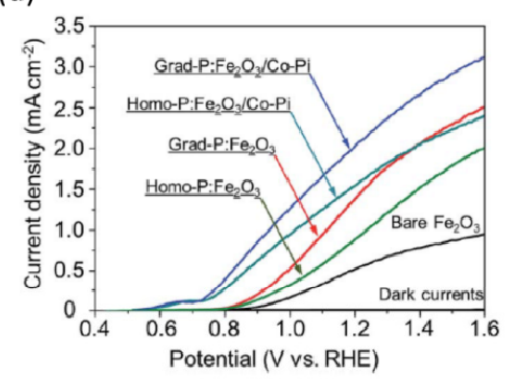

(c)

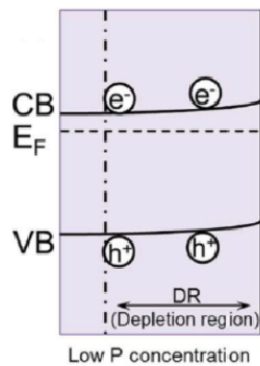

(d)

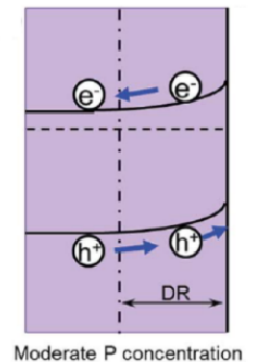

(b)

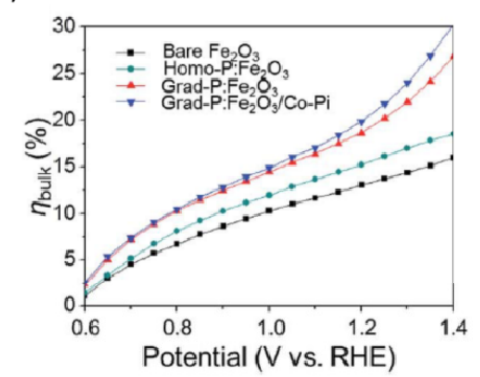

(e)

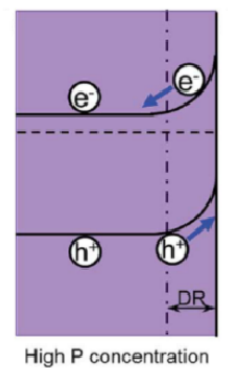

(f)

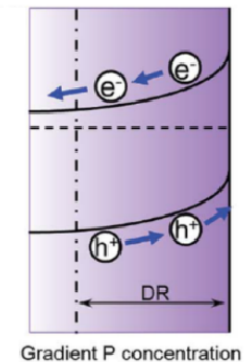

Fig. 7. (a) $J$ - $V$ curves of different photoanodes based on hematite. (b) Charge separation efficient in bulk; (c-e) the band bending schemes in hematite with different P concentrations. (f) Gradient P concentration; EF is the Fermi level. Adapted with permission from Ref. [51]. Copyright (2017) Royal Society of Chemistry.

atite as an overlayer (underlayer), which substantially decreases $\tau_{2}$ and increases $\tau_{1}$ simultaneously.

Chen et al. [60] fabricated a $\mathrm{Ti} / \mathrm{Au} / \mathrm{Fe}_{2} \mathrm{O}_{3}$ structured photoanode for water oxidation, wherein Au NP layers were both on top and under the hematite layer. Notably, Au NPs form a junction with hematite and improve the charge separation efficiency (in this case, Au NPs distributed in the hematite-FTO substrate interface act as electron collectors and promote the separation of electron-hole pairs). A similar result has also been reported by other researchers [61]. The hematite electrode loaded with a low amount of Au NPs showed a $\mathrm{Au}$-semiconductor contact (Schottky contact), thereby resulting in Fermi level equilibration, which ensued an improved charge transport efficiency.

In addition to the metal-semiconductor junction, the S-S junction is also used to enhance charge separation. Semiconductor-semiconductor junctions can be simply categorized into homojunctions and heterojunctions. Ma et al. [62] fabricated a photoanode consisting of Mg-doped and P-doped hematite nanorods. The homojunction structure had a high charge separation capacity; experimental and density functional theory (DFT) analyses indicated that the excellent PEC performance was due to the improved conductivity and favorable charge separation efficiency, which were caused by the built-in electric field.

The S-S heterojunction can be divided into three types according to the relative positions of the $\mathrm{CB}$ and $\mathrm{VB}$ between the semiconductors. As shown in Fig. 8, three types of heterojunctions are denoted by types I, II, and III according to their relative band edge positions (corresponding to Fig. 8(a), (b), and (c), respectively). Here, only type II heterojunctions can result in all-round efficient charge separation $[63,64]$. It was designed and prepared for a $\mathrm{U}_{3} \mathrm{O}_{8} / \mathrm{Fe}_{2} \mathrm{O}_{3}$ heterojunction-structured electrode $_{3} \mathrm{O}_{8}$ layer was under the $\mathrm{Fe}_{2} \mathrm{O}_{3}$ layer $)$ [65]. The $\mathrm{U}_{3} \mathrm{O}_{8} / \mathrm{Fe}_{2} \mathrm{O}_{3}$ photoanode attained a photocurrent density of $2.43 \mathrm{~mA} \mathrm{~cm}^{-2}$ at $1.23 \mathrm{~V}$ (vs. RHE) in a $1 \mathrm{M} \mathrm{NaOH}$ solution (approximately twice that of the bare $\mathrm{Fe}_{2} \mathrm{O}_{3}$ photoanode) and an eariler onset potential. The enhanced PEC performance of the $\mathrm{U}_{3} \mathrm{O}_{8} / \mathrm{Fe}_{2} \mathrm{O}_{3}$ system is attributed to the excellent charge separation capacity. A faster photoinduced electron injected from $\mathrm{Fe}_{2} \mathrm{O}_{3}$ to $\mathrm{U}_{3} \mathrm{O}_{8}$ resulted from the built-in electric field at the $\mathrm{U}_{3} \mathrm{O}_{8} / \mathrm{Fe}_{2} \mathrm{O}_{3}$ heterojunction, which was verified by in situ X-ray absorption spectroscopy and transient absorption spectroscopy measurements. The DFT and experimental results imply that the $\mathrm{U}_{3} \mathrm{O}_{8} / \mathrm{Fe}_{2} \mathrm{O}_{3}$ system could be a type II band alignment, leading to a strengthened charge carrier separation. Similarly, core-shell heterojunction photoanodes were synthesized using hybrid microwave annealing [66], wherein the core and shell were $\mathrm{Fe}_{2} \mathrm{O}_{3}$ nanorods and $\mathrm{FeNbO}_{4}$ thin layers, respectively. A higher water oxidation activity was obtained for the $\mathrm{Fe}_{2} \mathrm{O}_{3} @ \mathrm{FeNbO}_{4}$ electrode (with a photocurrent density of 2.24

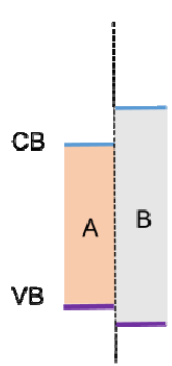

(a)

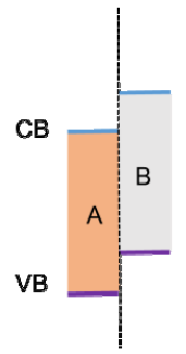

(b)

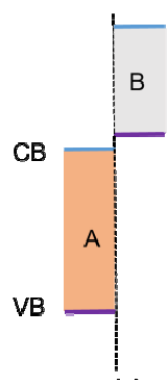

(c)
Fig. 8. Types of heterojunctions. (a) type I; (b) type II; (c) type III. (the band bending is not shown). 

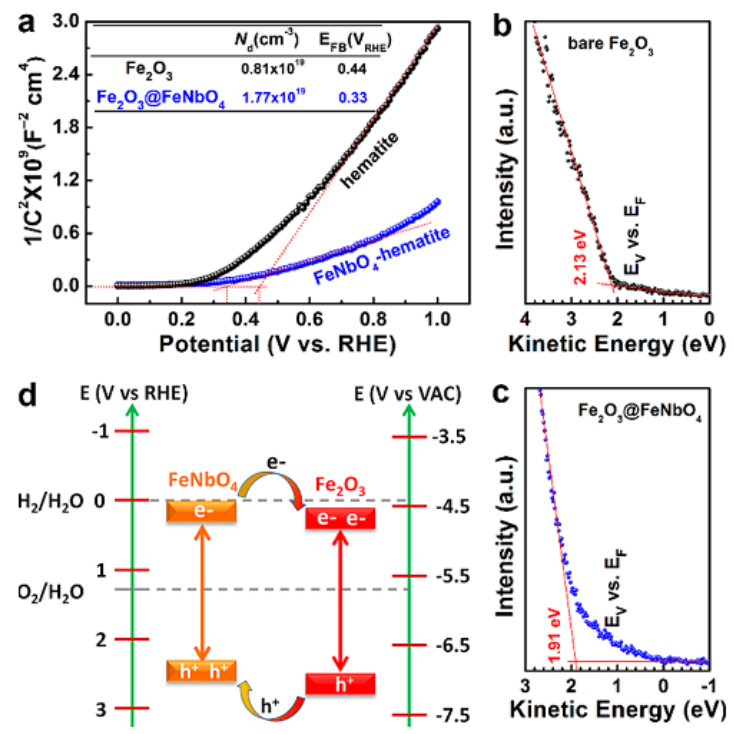

Fig. 9. Mott-Schottky plots (a) and UPS spectra for hematite (b) and $\mathrm{Fe}_{2} \mathrm{O}_{3} @ \mathrm{FeNbO}_{4}$ nanorods (c), and (d) corresponding band alignment (d). Adapted with permission from Ref. [66]. Copyright (2018) American Chemical Society.

$\mathrm{mA} \mathrm{cm}{ }^{-2}$ at $1.23 \mathrm{~V}$ (vs. RHE), which was approximately twice that of the bare $\mathrm{Fe}_{2} \mathrm{O}_{3}$ electrode). The superior PEC performance of the $\mathrm{Fe}_{2} \mathrm{O}_{3} @ \mathrm{FeNbO}_{4}$ system is attributable to the improvement in the bulk and surface separation efficiency. The Mott-Schottky (Fig. 9(a)) and ultraviolet photoelectron spectroscopy (UPS) (Fig. 9(b,c)) results indicate that the band alignment of the $\mathrm{Fe}_{2} \mathrm{O}_{3} @ \mathrm{FeNbO}_{4}$ heterojunction is a type II alignment (Fig. 9(d)), which favors charge separation.

\subsubsection{Passive recombination center (increase $\tau_{1}$ )}

Intermediate defect states are produced as recombination centers because of the strong interactions between the substrate and hematite [67]. Inserting a metal oxide layer between

\section{Table 2}

Summary of studies on enhancing the separation efficiency of bulk semiconductors.

\begin{tabular}{|c|c|c|c|}
\hline Samples & Electrolyte & $\begin{array}{c}\text { Photocurrent density } \\
(\mathrm{mA} \mathrm{cm}-2 \text {, at } 1.23 \mathrm{~V} \text { vs } \\
\text { RHE) }\end{array}$ & Ref. \\
\hline $\begin{array}{l}\text { Ultrafine } \mathrm{Ti}-\mathrm{Fe}_{2} \mathrm{O}_{3} \\
\text { nanowire array }\end{array}$ & $1 \mathrm{M} \mathrm{NaOH}$ & 0.90 & [44] \\
\hline $\mathrm{TiO}_{2} / \mathrm{Ti}: \mathrm{Fe}_{2} \mathrm{O}_{3} \mathrm{BNR}$ & $1 \mathrm{M} \mathrm{KOH}$ & 2.50 & {$[45]$} \\
\hline $\begin{array}{l}\text { Ti-modified mesopo- } \\
\text { rous } \mathrm{Fe}_{2} \mathrm{O}_{3}\end{array}$ & $1 \mathrm{M} \mathrm{NaOH}$ & 4.30 & {$[50]$} \\
\hline Sn-doped $\mathrm{Fe}_{2} \mathrm{O}_{3}$ & $1 \mathrm{M} \mathrm{NaOH}$ & 1.83 & {$[54]$} \\
\hline P-doped $\mathrm{Fe}_{2} \mathrm{O}_{3}$ & $1 \mathrm{M} \mathrm{NaOH}$ & 2.70 & [57] \\
\hline Grad P-doped $\mathrm{Fe}_{2} \mathrm{O}_{3}$ & $1 \mathrm{M} \mathrm{KOH}$ & 1.48 & [51] \\
\hline $\mathrm{Ti}, \mathrm{Mg}$ co-doped $\mathrm{Fe}_{2} \mathrm{O}_{3}$ & $1 \mathrm{M} \mathrm{NaOH}$ & 1.08 & [58] \\
\hline $\mathrm{Ti} / \mathrm{Au} / \mathrm{Fe}_{2} \mathrm{O}_{3}$ & $1 \mathrm{M} \mathrm{NaOH}$ & 0.51 & {$[60]$} \\
\hline $\begin{array}{l}\text { Mg-doped } \mathrm{Fe}_{2} \mathrm{O}_{3} / \\
\text { P-doped } \mathrm{Fe}_{2} \mathrm{O}_{3}\end{array}$ & $1 \mathrm{M} \mathrm{KOH}$ & 2.40 & [62] \\
\hline $\mathrm{U}_{3} \mathrm{O}_{8} / \mathrm{Fe}_{2} \mathrm{O}_{3}$ & $1 \mathrm{M} \mathrm{NaOH}$ & 2.43 & {$[65]$} \\
\hline $\mathrm{Fe}_{2} \mathrm{O}_{3} @ \mathrm{FeNbO}_{4}$ & $1 \mathrm{M} \mathrm{NaOH}$ & 2.24 & {$[66]$} \\
\hline $\mathrm{Fe}_{2} \mathrm{O}_{3} / \mathrm{TiO}_{2}$ & $1 \mathrm{M} \mathrm{KOH}$ & 2.90 & [70] \\
\hline
\end{tabular}

FTO and hematite can substantially retard the interface recombination (increased $\tau_{1}$ ). Liang et al. [68] investigated the influence of the $\mathrm{SnO}_{2}$ interfacial layer in hematite electrodes. After eliminating the possibility of unintentional $\mathrm{Sn}^{4+}$ doping from $\mathrm{SnO}_{2}$, the $\mathrm{SnO}_{2}$ interfacial layer plays the roles of surface state passivation to decrease recombination. Luo et al. [45] fabricated a $\mathrm{TiO}_{2}$ underlayer of hematite, leading to an excellent PEC performance, while suppressing recombination by alleviating the lattice mismatch between the substrate and hematite.

In addition, the grain boundaries of materials have been regarded as a charge blocking component [69], which can act as the recombination center. Feng et al. [70] provided an efficient strategy to enhance charge separation by $\mathrm{TiO}_{2}$ decoration at the grain boundaries in hematite, and the PEC performance enhancement was ascribed to a decrease in bulk recombination loss.

\subsection{Promotion of the surface injection efficiency ( $\left.\eta_{\mathrm{inj}}\right)$}

Compared with the two processes mentioned above, the surface hole injection process is more complicated. The possible processes at the semiconductor-water solution interface (Fig. 10) in PEC water splitting include the following: (1) the holes directly oxidize water molecules; (2) the holes are trapped by the surface states; (3) the holes trapped by the surface state oxidize water molecules; (4) the holes trapped by the surface state recombine; (5) the electrons from the CB reduce oxygen (the reverse reaction of water oxidation, i.e., the oxygen reduction reaction), and (6) the direct recombination process between the electrons of the CB and holes of the VB. The surface state can be a recombination center or a medium of charge transfer [71]. Here, the surface recombination process occurs after the photogenerated holes arrive at the surface, including surface state trap recombination (process 3 in Fig. 10) and back electron-hole recombination (process 6 in Fig. 10) [72].

We can make a simple classification of these processes as follows: (I) Recombination process, including process 4 (as-

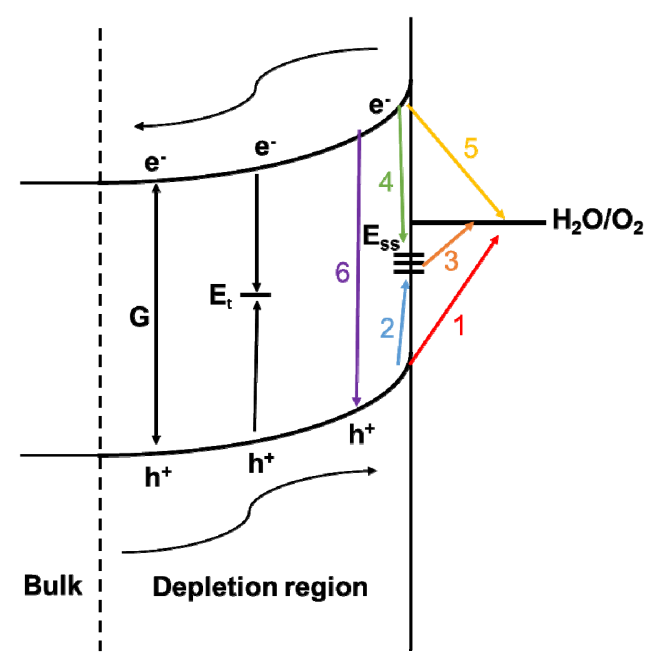

Fig. 10. Processes that may exist at the semiconductor-solution interface. $\mathrm{G}$ represents the generation of electron-hole pairs; $E_{\mathrm{t}}$ is trap energy level in the bulk semiconductor; and $E_{\mathrm{ss}}$ is the surface state energy level. 
suming that surface indirect recombination mainly occurs in the surface state) and process 6; (II) Water oxidation processes, including processes 1 and 3, and (III) Back reaction, including process 5 (the reverse reaction of water oxidation). Hence, to promote the surface injection efficiency, three strategies can be applied: (I) reducing the surface recombination, (II) accelerating the water oxidation reaction kinetics, and (III) suppressing the back reactions.

\subsubsection{Reducing surface recombination}

The holes that migrated from the bulk accumulated on the hematite surface and resulted in severe recombination. Two pinning effects must be considered for semiconductors: the applied potential drop located on the space charge layer of semiconductors, and the Helmholtz layer located on the semiconductor-solution interface (neglected diffuse layer in solution). Owing to the significantly greater Helmholtz capacitance $\left(\mathrm{C}_{\mathrm{H}}\right)$ relative to the space charge layer capacitance (Csc), the main applied potential drop will be in the space charge layer of semiconductors, while the Helmholtz potential is a constant; this leads to the near-unchanged band edge position of the semiconductor (band edge pinning effect, Fig. 11(a)). For the band edge pinning condition, the increased applied potential enhances band bending, which contributes to photogenerated carrier separation. However, if there are surface states, the relative position of the Fermi level and the band edge positions at the surface appear to be fixed, and band bending remains unchanged even when the applied potential changes (Fermi level pinning effect, Fig. 11(b)), which hardly contributes to photogenerated carrier separation. Thus, a widely employed means to reduce surface recombination is to passivate the surface state. In addition, decreasing the electron density of the semiconductor surface can also retard surface recombination.

\subsubsection{Passivating surface state}

For the passivating surface state, the most commonly used method is to coat a thin passivation film to cover the hematite surface. For instance, Bahnemann et al. [74] reported a surface passivation by coating a $\mathrm{TiO}_{2}$ layer over a hematite electrode. The loading of the $\mathrm{TiO}_{2}$ layer was accomplished by a simple dipping-annealing process, whose thickness was estimated to be $<2 \mathrm{~nm}$. The PEC water splitting performance measurement is shown in Fig. 12(a). The results revealed that a nearly 3.5-fold improvement in the photocurrent was observed after $\mathrm{TiO}_{2}$ coating. Simultaneously, according to the literature [75], because of the existence of the surface state, a partial Fermi level pinning effect will occur at the semiconductor-solution interface, which results in a low photovoltage (the photovoltage is equal to the difference between the open-circuit po-
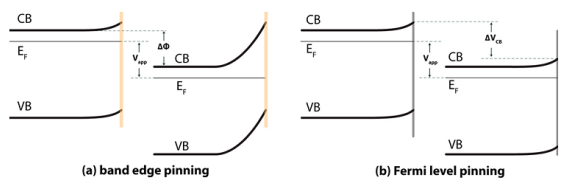

Fig. 11. Band edge pinning diagrams (a) and Fermi level pinning (b) for a photoanode system. Adapted with permission from Ref. [73]. Copyright (2015) American Chemical Society. (a)

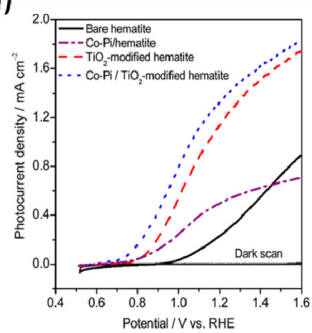

(b)

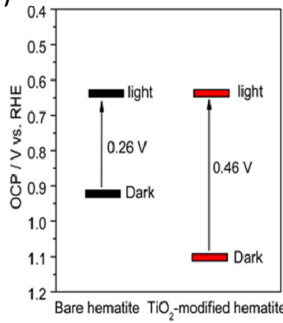

Fig. 12. (a) $J$ - $V$ curves for PEC water oxidation based on different hematite electrodes under illumination (1 Sun, AM 1.5) from 1.0 M NaOH solution; (b) OCP in the dark and under illumination for hematite electrodes. Adapted with permission from Ref. [74]. Copyright (2015) American Chemical Society.

tentials (OCPs) under dark and illumination conditions) and a more positive onset potential. To understand the role of $\mathrm{TiO}_{2}$, OCP measurement was implemented, and the results are shown in Fig. 12(b). The photovoltage significantly increased from $0.26-0.46 \mathrm{~V}$ after $\mathrm{TiO}_{2}$ layer modification. Hence, the authors concluded that the role of the $\mathrm{TiO}_{2}$ overlayer is for surface state passivation, which decreases surface recombination and increases photovoltage. Grätzel et al. prepared a hematite electrode that was coated with an $\mathrm{Al}_{2} \mathrm{O}_{3}$ thin film using atomic layer deposition [76]. The PEC measurement results showed that the $\mathrm{Al}_{2} \mathrm{O}_{3}$ coating overlayer reduced the overpotential of hematite (approximately $100 \mathrm{mV}$ ) and evidently promoted the photocurrent (approximately 3.5 times that of the bare electrode at 1 $\mathrm{V}$ (vs. RHE)). The electrochemical impedance measurements under dark conditions showed that the $\mathrm{Al}_{2} \mathrm{O}_{3}$ overlayer led to increased $C_{\mathrm{SC}}$ and decreased $C_{\mathrm{H}}$ with increasing applied potential. This could be interpreted by the surface state passivation. In addition, photoluminescence (PL) spectroscopy measurements revealed that the $\mathrm{Al}_{2} \mathrm{O}_{3}$ overlayer decreased the non-radiative recombination of the excitons from the surface state trapping, further confirming that the function of the $\mathrm{Al}_{2} \mathrm{O}_{3}$ overlayer passivates the surface state. The same group also investigated the effects of a $\mathrm{Ga}_{2} \mathrm{O}_{3}$ overlayer on hematite photoanodes [77]. The surface state capacitance $\mathrm{C}_{\text {trap was obtained }}$ through an equivalent circuit, and the density of surface state (DOS) under different potentials was calculated. The results showed that the potential corresponding to the maximum DOS value shifted negatively (which was consistent with the onset potential) after the coating of the $\mathrm{Ga}_{2} \mathrm{O}_{3}$ overlayer. Such a description verified that the $\mathrm{Ga}_{2} \mathrm{O}_{3}$ overlayer passivated the surface states and affected the energetic distribution of the trap states.

Apart from the overlayer deposition, several intrinsic modification processes to the photoanode materials can also reduce the surface states. Firstly, the relationship between the annealing temperature and the surface state in the hematite electrode was investigated [78]. The correlation between the onset potential and surface state level can be obtained by a simple cyclic voltammetry (CV) measurement after PEC pre-oxidation of the surface state [79-81]. To understand the relationship between the annealing temperature and surface state, CV measurements were performed after the pre-oxidation of the samples an- 


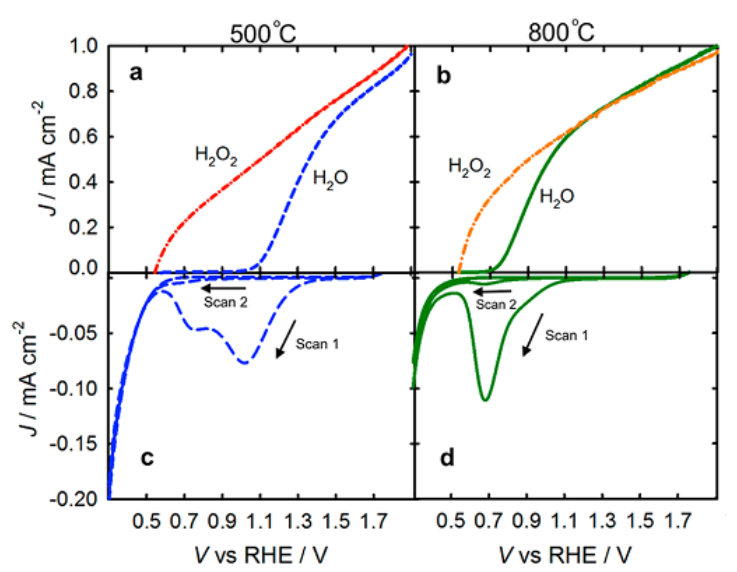

Fig. 13. $J-V$ curves under $\mathrm{H}_{2} \mathrm{O}$ and $\mathrm{H}_{2} \mathrm{O}_{2}$ oxidation conditions for hematite electrodes annealed at $500^{\circ} \mathrm{C} \mathrm{(a)} \mathrm{and} 800^{\circ} \mathrm{C}$ (b); CV curves scanned at $1 \mathrm{~V} \mathrm{~s}^{-1}$ under dark conditions for the electrodes annealed at $500{ }^{\circ} \mathrm{C}$ (c and $800{ }^{\circ} \mathrm{C}$ (d). Adapted with permission from Ref. [78]. Copyright (2014) American Chemical Society.

nealed at 500 and $800{ }^{\circ} \mathrm{C}$, respectively. In Fig. 13(c), two peaks, which can be assigned to two surface states, can be observed in the sample annealed at $500{ }^{\circ} \mathrm{C}$. However, at an annealing temperature of $800{ }^{\circ} \mathrm{C}$, the peak located at approximately $1 \mathrm{~V}$ (vs. RHE) disappeared, and the onset potential also exhibited a cathodic shift (Fig. 14(d)). The peak potential of the surface state corresponds to the onset potential of the photocurrent for water oxidation (Figs. 13(a,b)). High-temperature treatment can remove one of the two types of surface states. Recently, the acid treatment of hematite has been considered as a useful method to passivate surface electron traps [82,83]. Li et al. [83] found that acid treatment of hematite effectively suppressed surface recombination. The Mott-Schottky measurement results demonstrated that the donor density significantly increased after the acid treatment. Transient absorption spectroscopy and transient photocurrent measurements showed that the acid treatment resulted in an increased photogenerated electron detrapping rate because of the improved conductivity and
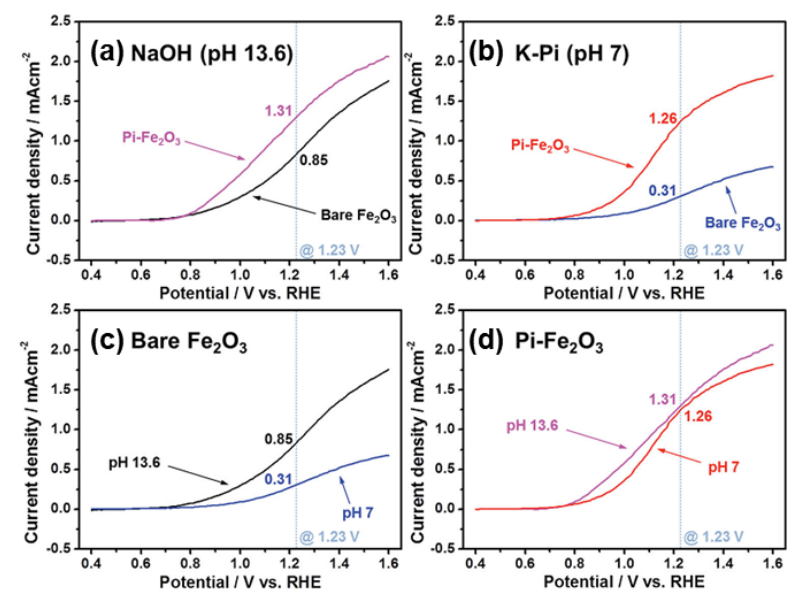

Fig. 14. $J-V$ curves of $\mathrm{Fe}_{2} \mathrm{O}_{3}$ electrodes under illumination in different pH electrolytes (1 Sun, AM 1.5): at pH 13.6 (a) and pH 7 (b) for the bare $\mathrm{Fe}_{2} \mathrm{O}_{3}$ (c) and $\mathrm{Pi}-\mathrm{Fe}_{2} \mathrm{O}_{3}$ (d) electrodes. Adapted with permission from Ref. [86]. Copyright (2014) Wiley. passivation of surface electron traps. Wang et al. [84] reported a facile re-growth strategy for the hematite electrode to reduce surface disorders and achieved an unprecedented low onset potential. All the above-mentioned methods effectively decrease the defects and passivate the surface states, which suppress surface recombination.

\subsubsection{Decreasing electron density}

In addition to passivating the recombination centers, decreasing the electron density and deepening the depletion layer will be conducive to retarding the surface recombination of hematite photoanodes. Durrant et al. used a transient absorption technology to study the roles of the overlayers on hematite photoanodes for water splitting [85]. Ultrathin $\mathrm{Ga}_{2} \mathrm{O}_{3}$ and $\mathrm{Co}_{2} \mathrm{O}_{3}$ films were deposited on the hematite surface. The transient spectrum results showed that the potential of the long-lived holes (which were rather related to the water oxidation reaction) would cathodically shift after surface modification by the overlayers $\left(\mathrm{Ga}_{2} \mathrm{O}_{3}\right.$ and $\left.\mathrm{Co}_{2} \mathrm{O}_{3}\right)$, which was consistent with the onset potential in the PEC measurements. However, the lifetime of long-lived holes is independent of the overlayers under bias, which implies that no photogenerated holes are transferred to the overlayers. The authors considered that the overlayers enhanced the spatial extent of the space charge/electron depletion layer. Lee et al. [66] also reported the heterojunction $\mathrm{Fe}_{2} \mathrm{O}_{3} @ \mathrm{FeNbO}_{4}$ photoanode for water oxidation, which not only improved the bulk separation efficiency but also enhanced the surface injection efficiency (from $43 \%$ for $\mathrm{Fe}_{2} \mathrm{O}_{3}$ electrode at $1.23 \mathrm{~V}$ (vs. RHE) to 78\% for the $\mathrm{Fe}_{2} \mathrm{O}_{3} @ \mathrm{FeNbO}_{4}$ electrode). The chopped $J-V$ curves showed that the transient photocurrents increased after the formation of the heterojunction because of the electron depletion effect of the internal electric field in the type II heterojunction. The authors also deposited a cocatalyst $\mathrm{NiFeO}_{x}$ layer on a $\mathrm{Fe}_{2} \mathrm{O}_{3} @ \mathrm{FeNbO}_{4}$ electrode, which effectively passivated the surface state, thereby improving the surface injection efficiency. Notably, the $\mathrm{pH}$ of the electrolyte significantly affects the surface environment of the semiconductor films and is related to surface recombination. Lee et al. [86] explored the PEC performance of hematite photoanodes in neutral ( $\mathrm{pH} 7$ potassium phosphate (K-Pi) buffer) and basic $(\mathrm{pH}=13.6 \mathrm{NaOH})$ solutions. The performance for water splitting in the alkaline solution was superior to that in the neutral one (Fig. 14(c)) in terms of both photocurrent density and onset potential. After a simple phosphate treatment was performed on the bare $\mathrm{Fe}_{2} \mathrm{O}_{3}$ electrode, the $\mathrm{Fe}_{2} \mathrm{O}_{3}$ electrode $\left(\mathrm{Pi}-\mathrm{Fe}_{2} \mathrm{O}_{3}\right)$ exhibited outstanding performances in the neutral and alkaline solutions (Figs. 14(a,b)) compared to the bare samples; however, only a slight distinction in the performance of $\mathrm{Pi}-\mathrm{Fe}_{2} \mathrm{O}_{3}$ was detectable when tested in neutral and alkaline electrolytes (Fig. 14(d)). The authors observed that the adsorption of phosphate ions on the $\mathrm{Fe}_{2} \mathrm{O}_{3}$ surface changed the isoelectric point (from 8.3 to 4.8 ) of the hematite photoanodes, thereby resulting in a negative charge on the surface of the neutral and alkaline solutions. The negative charge on the surface could induce an electrostatic field and was beneficial for the separation of electron-hole pairs, while suppressing surface recombination. 


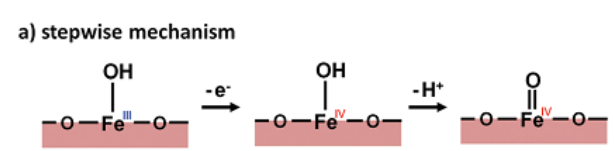

b) concerted mechanism

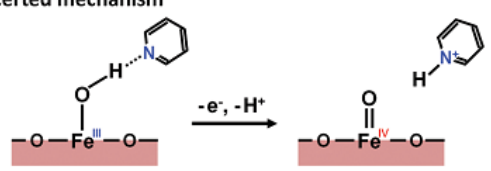

Fig. 15. Proposed RDS for water oxidation on hematite. (a) Stepwise electron/proton transfer pathway; (b) CPET transfer pathway. Adapted with permission from Ref. [90]. Copyright (2016) Royal Society of Chemistry.

\subsubsection{Acceleration of the kinetics of water oxidation reaction}

It is well known that the water oxidation reaction is a typical proton-coupled electron transfer reaction [87]. To date, the detailed reaction mechanism remains unclear. In most water oxidation reaction kinetic models, $\mathrm{O}-\mathrm{O}$ bond formation is generally the rate-determining step (RDS), which includes two pathways: water molecule nucleophilic attack (WNA) and radical coupling (I2M)) [88]. For the hematite photoanodes in PEC water oxidation, the slow kinetic activity significantly restricts the hole injection efficiency. A great effort has been made in the past decades to understand the reaction mechanism in PEC water oxidation. Durrant et al. [89] performed a rate law analysis of the order of water oxidation on a hematite photoanode. The surface hole density was estimated by the photoinduced absorption spectroscopy signal at $650 \mathrm{~nm}$. The results indicated that a slow and first-order reaction appeared with a low accumulated hole density, whereas with the increased surface accumulated hole density (sufficient to enable the oxidation of the nearest neighbor metal atoms), a faster and third-order mechanism replaced the original first-order reaction. This accumulated hole density-related transition mechanism on the surface was first revealed.

Ishikawa et al. [90] investigated the proton-coupled electron transfer process for hematite in a neutral electrolyte. The authors detected a change in the RDS after adding pyridine derivatives to the electrolyte (Fig. 15); this was supported by the kinetic isotope effect (KIE) experiment and pH-dependent measurement. In the bare electrolyte (without the proton ac-

a

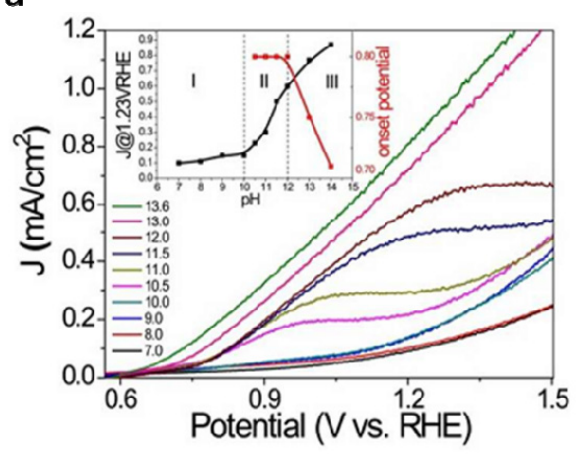

ceptor), in the $\mathrm{pH}$ range from 5-9, the onset potential remained constant. Upon adding a proton acceptor (such as pyridine), a Nernst behavioral change was observed, which implied that a concerted proton-coupled electron transfer (CPET) process was induced by adding a proton acceptor. Moreover, KIE experiments revealed that the KIE value increased from 1.18-2.58 upon the inclusion pyridine in the electrolyte, indicating that the RDS was related to proton transfer. However, when the $\mathrm{pH}$ of the electrolyte increased to $>10$ (such as 13), the performance of the hematite photoanodes was insensitive to the proton acceptor, which indicated the existence of other pathways at high $\mathrm{pH}$ conditions. Zhao et al. $[88,91]$ comprehensively studied the reaction pathways on hematite for water splitting under different $\mathrm{pH}$ conditions. Poor activities were observed from pH 7-10 (Fig. 16(a)). Above a pH of 12, as the $\mathrm{pH}$ rose in the Nernstian fashion (approximately $59 \mathrm{mV} / \mathrm{pH}$ ), the onset potential decreased gradually; however, the photocurrent density continued to increase. The KIE value (Fig. 16(b)) displayed a significantly downward tendency from $\mathrm{pH}$ of 7-13.6 at $0.9-1.2 \mathrm{~V}$ (vs. RHE for a $\mathrm{pH}$ of 1.5-3.1 at $\mathrm{pH} 9-11$; approximately 1 at $\mathrm{pH} \geqslant 13$ ), which implied that the RDS step did not involve proton transfer under strong alkaline conditions. Thereafter, the authors studied the reaction order of the hole transfer. The reaction orders of 1.1 and 2.4 at $\mathrm{pH}$ values of 10 and 13.6 were obtained, respectively. Thus, the authors hypothesized that the reaction pathways depended on $\mathrm{pH}$ conditions, as shown in Fig. 17. Furthermore, the 0-0 bond formation mechanism switched from WNA at pH 7-10 (Fig. 17(a)) to I2M at pH 13.6 (Fig. 17(b)), corresponding to their reaction orders. A surface superoxide species that is hydrogen-bonded to the adjacent hydroxyl group was probed by an operando Fourier-transform infrared spectroscopy technique at an electrolyte $\mathrm{pH}$ of 8; for increasing $\mathrm{pH}$ values, the peak intensity gradually decreased and completely disappeared at a $\mathrm{pH}$ of 11 , which further confirms the above-mentioned transformation mechanism with $\mathrm{pH}$.

Meanwhile, some efforts have been made in the past decades to accelerate the water oxidation reaction. Xie et al. [38] developed an F-doped strategy to enhance the PEC activity of hematite for water oxidation. The F-doped hematite improved the intrinsic water oxidation activity, which was confirmed by the remarkably high dark current and low Tafel slope after

b

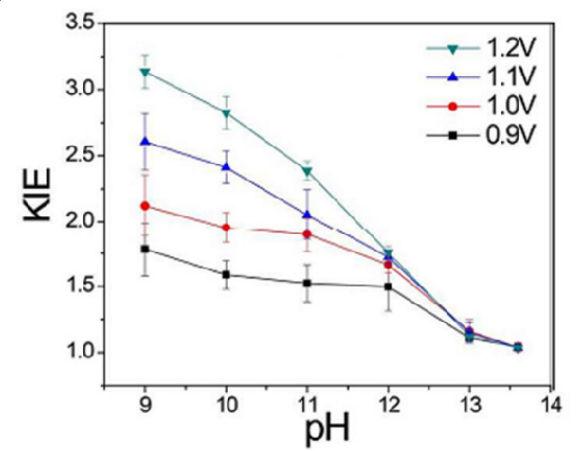

Fig. 16. (a) $J-V$ scans under illumination in a $0.5 \mathrm{M} \mathrm{NaClO}_{4}$ solution at different $\mathrm{pH}$ levels; (b) KIE values calculated from the steady photocurrent ratio in $\mathrm{H}_{2} \mathrm{O}$ and $\mathrm{D}_{2} \mathrm{O}$ at various electrolyte $\mathrm{pH}$ levels. Adapted with permission from Ref. [91]. Copyright (2016) American Chemical Society. 


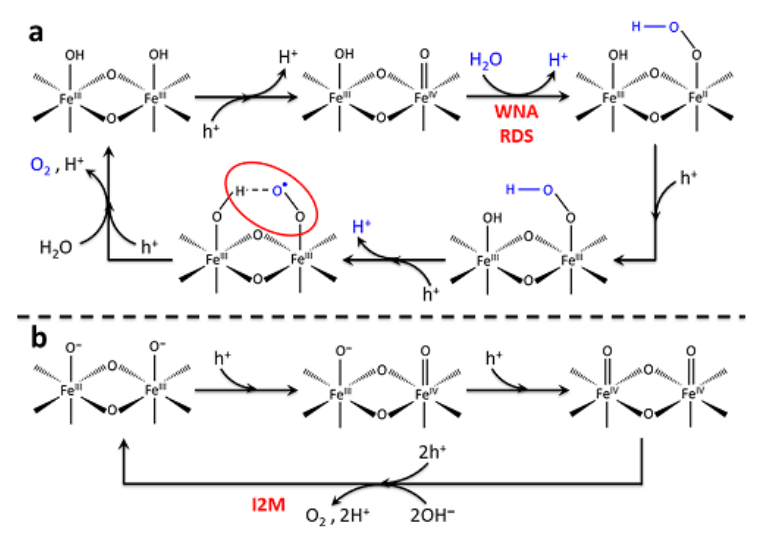

Fig. 17. WNA (a) and I2M (b) mechanisms on hematite surfaces. Adapted with permission from Ref. [88]. Copyright (2018) American Chemical Society.

doping. The authors believed that F-doping was favorable toward significantly enhancing the OER activity, thereby contributing to the formation of Fe-F bonds, which could enrich the positive charge of $\mathrm{Fe}$ sites; this facilitated $\mathrm{OH}^{-}$adsorption on the active sites. It has been reported that performing a simple alkali treatment to the hematite electrode can significantly enhance the water oxidation reaction activity [92]. Furthermore, TEM measurements revealed the formation of a thin layer anchored with hydroxyl groups on the hematite surface after the alkali treatment. The $J-V$ curves under light irradiation and dark conditions indicated that the thin overlayer on the hematite photoanodes promoted the water oxidation reaction.

Besides optimizing the intrinsic material, introducing an OER catalyst on the hematite surface is another effective means to enhance the hole injection efficiency. Notably, the inorganic catalyst layer deposited on the hematite surface can play different roles, such as decreasing electron-hole recombination and accelerating OER kinetics. Wang et al. [93] compared a heterogenized molecular Ir catalyst (het-WOC) and heterogeneous oxide catalysts $\left(\mathrm{IrO}_{x}\right)$ on hematite for PEC water oxidation. Intensity-modulated photocurrent spectroscopy (IMPS) is a useful approach for analyzing the surface kinetics of semiconductors. This technology uses a small sinusoidal modulation of light intensity to measure the phase and magnitude of the photocurrent response as a function of frequency [94]. We can obtain two key rate constants (recombination rate constant $k_{\text {re }}$ and transfer rate constant $k_{\text {tr }}$ ) via IMPS measurements. As shown in Fig. 18, $k_{\text {tr }}$ and $k_{\text {re }}$ were observed for three different
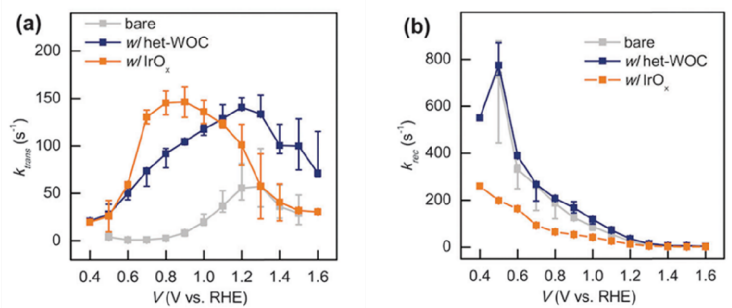

Fig. 18. Summary of IMPS data for three different photoelectrodes; (a)

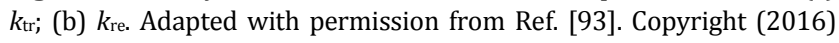
Royal Society of Chemistry. electrodes. For the hematite electrode with het-WOC and $\operatorname{IrO}{ }_{x}$, the values of $k_{\text {tr }}$ were significantly higher than those for the bare hematite and increased with the applied potentials. However, the values of $k_{\text {re }}$ for the bare hematite and the hematite with het-WOC are rather identical and significantly higher than that for the hematite electrode with $\mathrm{IrO}_{x}$. The values of $k_{\mathrm{re}}$ for these three electrodes decrease with increasing potentials. These results indicate that the $\mathrm{IrO}_{x}$ catalyst not only accelerates OER kinetics, but also retards electron-hole recombination compared to the molecular Ir catalyst, which minimally contributes to the reduced recombination. Other catalyst layers, such as cobalt-phosphate (CoPi) $[95,96], \mathrm{CoO}_{x}$ [97], $\mathrm{FeOOH}$ [98], NiCoAl layered double hydroxides (NiCoAl-LDH) [99], and CoAl-layered double hydroxides (CoAl-LDH) [100], have also been reported, which can enhance the hole transfer kinetics and decrease surface recombination. Kandiel et al. [101] also reported a Co-based OER catalyst using 3-aminopropionic acid as a bifunctional linker that linked cobalt ions to the hematite surface, and a higher photocurrent and water oxidation activity compared to the CoPi catalyst were obtained. In addition to inorganic catalysts, molecular catalysts have also been used to enhance the OER kinetics in hematite [102]. A molecular ruthenium catalyst (RuOEC) was synthesized to modify the hematite electrode, wherein 2,6-pyridine-dicarboxylic acid was applied as an anchor group to link the hematite and the RuOEC catalyst [103]. The RuOEC-modified hematite electrode exhibited a higher photocurrent than the pristine hematite, which illustrated that the molecular catalyst played an essential role in PEC water oxidation.

\subsubsection{Suppression of back reactions}

Suppressing the back reactions of OER kinetics is an essential pathway to enhance the hole injection efficiency of hematite. An efficient method to suppress back reactions involves the introduction of a blocking layer. As shown in Fig. 19, for some hematite electrodes with flawed films, the generation of the substrate-solution interface is caused by the incomplete coverage of the hematite film on the substrates. Consequently, the electrons in the substrate (such as FTO) transferred from hematite could react with the intermediate or product $\left(\mathrm{O}_{2}\right)$ and lower the hole utilization (Fig. 19(a)). Once a blocking layer has been introduced between the hematite film and the substrate (Fig. 19(b)), the substrate-solution interface is drastically reduced to suppress the back reactions.

For example, the effect of the $\mathrm{Nb}_{2} \mathrm{O}_{5}$ underlayer of hematite on PEC water oxidation has been intensively studied [104]. The

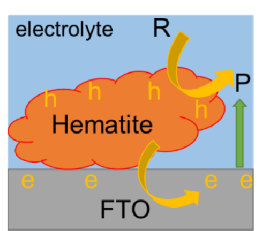

(a)

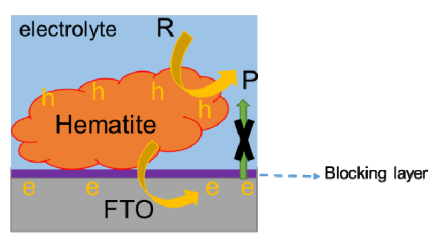

(b)
Fig. 19. Back reaction in the FTO-solution interface. (a) without a blocking layer; (b) with a blocking layer. $\mathrm{R}$ represents the reactant $\left(\mathrm{OH}^{-}\right.$ or $\mathrm{H}_{2} \mathrm{O}$ ). 


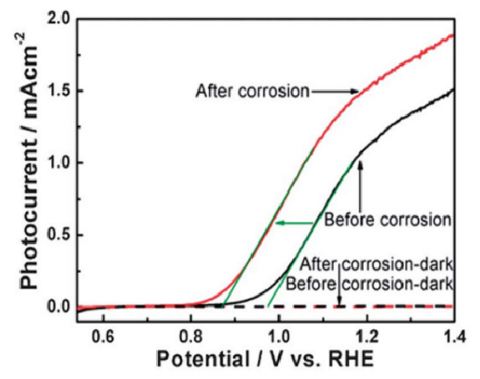

b

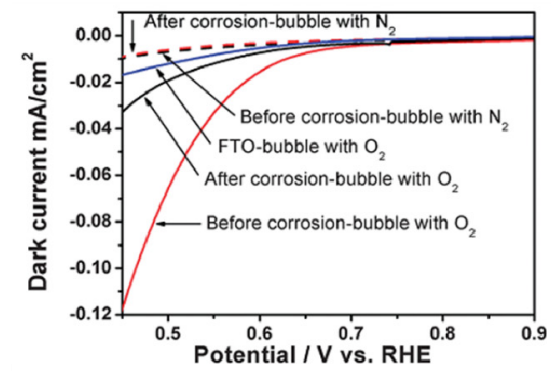

Fig. 20. (a) $J$ - $V$ curves of the $\mathrm{Ti}^{4+}$ doped $\mathrm{Fe}_{2} \mathrm{O}_{3}$ before and after surface corrosion in $1 \mathrm{M} \mathrm{NaOH}$; (b) Reduction dark current before and after surface corrosion in $1 \mathrm{M} \mathrm{NaOH}$, FTO substrate as a reference, and different gas bubbling $\left(\mathrm{N}_{2}\right.$ or $\left.\mathrm{O}_{2}\right)$ processes. Adapted with permission from Ref. [106]. Copyright (2014) Royal Society of Chemistry.

cathodic dark currents that have been measured in the presence of $\mathrm{Fe}^{\mathrm{II}}(\mathrm{CN})_{6}{ }^{4-} / \mathrm{Fe}^{\mathrm{III}}(\mathrm{CN})_{6}{ }^{3-}$ redox couples suggest that a $\mathrm{Nb}_{2} \mathrm{O}_{5}$ underlayer suppresses the back injection of electrons. Bouhjar et al. [105] used a thin hematite layer prepared via electrodeposition as a blocking layer to the subjective hematite, and an excellent PEC performance was achieved.

In addition, Zou et al. discovered that enhancing the photocurrent for Ti-doped hematite photoanodes by acid corrosion (Fig. 20(a)) [106]. The dark current, PL spectroscopy, and transient photocurrent measurements have revealed that enhancing the photocurrent is irrelevant toward improving the water oxidation kinetics and passivating surface state, but it is required to suppress the back reactions. The reduction dark current is shown in Fig. 20(b) for Ti-doped $\mathrm{Fe}_{2} \mathrm{O}_{3}$ before and after corrosion with different gas $\left(\mathrm{N}_{2}\right.$ or $\left.\mathrm{O}_{2}\right)$ bubbling processes. The dark current is rather negligible when $\mathrm{N}_{2}$ is bubbled into the electrolyte. Comparably, a significantly decreased $\mathrm{O}_{2}$ reduction current for Ti-doped $\mathrm{Fe}_{2} \mathrm{O}_{3}$ after corrosion can be observed, which implies the inactivation of the $\mathrm{O}_{2}$ reduction reaction after corrosion, thereby confirming the suppression of the back reactions.

\section{Conclusions and outlook}

Hydrogen production via water splitting using solar energy is believed to be a promising approach toward solving energy and environmental problems. Among the most commonly used photoanode materials for PEC water splitting, hematite is con-

Table 3

Reports on surface injection efficiency enhancement.

\begin{tabular}{|c|c|c|c|}
\hline Samples & Electrolyte & $\begin{array}{c}\text { Photocurrent density } \\
\left(\mathrm{mA} \mathrm{cm}^{-2} \text {, at } 1.23 \mathrm{~V} \text { vs }\right. \\
\text { RHE) }\end{array}$ & Ref. \\
\hline $\mathrm{TiO}_{2}$-modified $\mathrm{Fe}_{2} \mathrm{O}_{3}$ & $1 \mathrm{M} \mathrm{NaOH}$ & 1.20 & [74] \\
\hline Annealing at $800^{\circ} \mathrm{C} \mathrm{Fe}_{2} \mathrm{O}_{3}$ & $1 \mathrm{M} \mathrm{KOH}$ & $\sim 0.78$ & [78] \\
\hline Acid treatment $\mathrm{Fe}_{2} \mathrm{O}_{3}$ & $1 \mathrm{M} \mathrm{NaOH}$ & $\sim 1.30$ & [83] \\
\hline \multirow[t]{2}{*}{$\mathrm{Pi}-\mathrm{Fe}_{2} \mathrm{O}_{3}$} & $1 \mathrm{M} \mathrm{NaOH}$ & 1.31 & [86] \\
\hline & $0.1 \mathrm{M} \mathrm{KPi}$ & 1.26 & \\
\hline F-doped $\mathrm{Fe}_{2} \mathrm{O}_{3}$ & $1 \mathrm{M} \mathrm{KOH}$ & 2.52 & [38] \\
\hline Alkali treatment $\mathrm{Fe}_{2} \mathrm{O}_{3}$ & $1 \mathrm{M} \mathrm{NaOH}$ & 0.63 & [92] \\
\hline $\mathrm{Fe}_{2} \mathrm{O}_{3} / \mathrm{FeOOH}$ & $1 \mathrm{M} \mathrm{NaOH}$ & 1.21 & [98] \\
\hline $\mathrm{Fe}_{2} \mathrm{O}_{3} / \mathrm{RuOEC}$ & $1 \mathrm{M} \mathrm{KOH}$ & $\sim 2.20$ & [103] \\
\hline $\mathrm{Nb}_{2} \mathrm{O}_{5}$ underlayer of hematite & $1 \mathrm{M} \mathrm{NaOH}$ & $\sim 0.1$ & {$[104]$} \\
\hline Acid corrosion $\mathrm{Ti}-\mathrm{Fe}_{2} \mathrm{O}_{3}$ & $1 \mathrm{M} \mathrm{NaOH}$ & $\sim 1.7$ & {$[106]$} \\
\hline
\end{tabular}

sidered as an ideal material because of its abundance, high theoretical photocurrent, suitable band edge positions, non-toxicity, and high photochemical stability. In recent years, efficient strategies to promote the performance of hematite photoanodes have been developed. To date, a hematite photoelectrode with a record photocurrent density in PEC water splitting was fabricated by combining the strategies mentioned above [107]. Firstly, a hematite nanowire photoelectrode with an excellent light absorption and bulk charge separation capacity was fabricated, followed by hydrogen treatment and loading of an ultrathin $\mathrm{TiO}_{2}$ overlayer, which enhanced the electrical conductivity and decreased surface recombination, respectively. Finally, a CoPi catalyst was deposited on the hematite- $\mathrm{TiO}_{2}$ photoelectrode, which further improved the surface injection efficiency. Eventually, it attained a high photocurrent density of approximately $6 \mathrm{~mA} \mathrm{~cm}^{-2}$ at $1.23 \mathrm{~V}$ (vs. RHE) under 1 Sun illumination. However, it is still considerably lower than the theoretical value (12.6 $\mathrm{mA} \mathrm{cm}^{-2}$ ). For the ideal PEC photoanode, an earlier onset potential (approximately close to the flat potential) and a more saturated photocurrent curve (approximately close to the theoretical photocurrent) are necessary. The main limiting factors of the efficiency are bulk recombination that result from the extremely short hole-diffuse length, as well as low conductivity. In addition, a comprehensive understanding of the surface process is essential to enhance PEC performance. The mechanism of water oxidation remains under debate. Meanwhile, research on the efficiency and fabrication technology for large-area electrodes must be conducted for large-scale industrialization in the future.

\section{References}

[1] Y. Lei, Y. Wang, Y. Liu, C. Song, Q. Li, D. Wang, Y. Li, Angew. Chem. Int. Ed., 2020, 59, 2-21.

[2] L. Chen, Y. Song, Y. Liu, L. Xu, J. Qin, Y. Lei, Y. Tang, J. Energy Chem., 2020, 50, 395-401.

[3] P. Sharma, J. W. Jang, J. S. Lee, ChemCatChem, 2018, 11, 157-179.

[4] A. Fujishima, K. Honda, Nature, 1972, 238, 37-38.

[5] J. Huang, P. Yue, L. Wang, H. She, Q. Wang, Chin. J. Catal., 2019, 40, 1408-1420.

[6] L. Liu, T. Hu, K. Dai, J. Zhang, C. Liang, Chin. J. Catal., 2021, 42, 46-55.

[7] H. S. Han, S. Shin, D. H. Kim, I. J. Park, J. S. Kim, P.-S. Huang, J-K. Lee, I. S. Cho, X. Zheng, Energy Environ. Sci., 2018, 11, 1299-1306. 


\section{Graphical Abstract}

Chin. J. Catal., 2021, 42: 904-919 doi: 10.1016/S1872-2067(20)63712-3

Recent strategies to enhance the efficiency of hematite photoanodes in photoelectrochemical water splitting

Dinghua Zhou, Ke Fan * Dalian University of Technology

Widely applied strategies to enhance the photoelectrochemical performance of hematite photoanodes for water splitting.

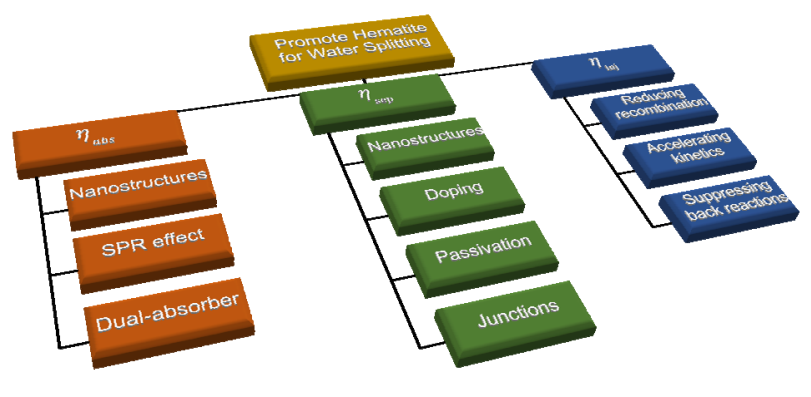

[8] Gurudayal, P. S. Bassi, T. Sritharan, L. H. Wong, J. Phys. D: Appl. Phys., 2018, 51, 473002.

[9] A. K. Singh, D. Sarkar, ChemCatChem, 2019, 11, 6355-6363.

[10] D. Wang, G. Chang, Y. Zhang, J. Chao, J. Yang, S. Su, L. Wang, C. Fan, L. Wang, Nanoscale, 2016, 8, 12697-12701.

[11] J. Li, Y. Qiu, Z. Wei, Q. Lin, Q. Zhang, K. Yan, H. Chen, S. Xiao, Z. Fan, S. Yang, Energy Environ. Sci., 2014, 7, 3651-3658.

[12] K. X. Wang, Z. Yu, V. Liu, M. L. Brongersma, T. F. Jaramillo, S. Fan, ACS Photonics, 2014, 1, 235-240.

[13] Y. Qiu, S. F. Leung, Q. Zhang, B. Hua, Q. Lin, Z. Wei, K. H. Tsui, Y. Zhang, S. Yang, Z. Fan, Nano Lett., 2014, 14, 2123-2129.

[14] E. Thimsen, F. Le Formal, M. Gratzel, S. C. Warren, Nano Lett., 2011, 11, 35-43.

[15] H. Gao, C. Liu, H. E. Jeong, P. Yang, ACS Nano, 2012, 6, 234-240.

[16] Cushing, K. Scott, N. Wu, Electrochem. Soc. Interface, 2013, 22, 63-67.

[17] S. K. Cushing, N. Wu, J. Phys. Chem. Lett., 2016, 7, 666-675.

[18] V. E. Ferry, J. N. Munday, H. A. Atwater, Adv. Mater., 2010, 22, 4794-4808.

[19] J. Li, S. K. Cushing, P. Zheng, F. Meng, D. Chu, N. Wu, Nat. Commun., 2013, 4, 2651.

[20] M. Okazaki, A. Furube, L. Y. Chen, J. Chem. Phys., 2020, 152, 041106.

[21] P. Peerakiatkhajohn, J. H. Yun, H. Chen, M. Lyu, T. Butburee, L. Wang, Adv. Mater., 2016, 28, 6405-6410.

[22] M. M. Momeni, A. Hallaj, Y. Ghayeb, R. Bagheri, Z. Song, H. Farrokhpour, Appl. Organomet. Chem., 2019, 33, e5087.

[23] F. Mei, Z. Li, K. Dai, J. Zhang, C. Liang, Chin. J. Catal., 2020, 41, $41-49$.

[24] Y. Huo, J. Zhang, K. Dai, Q. Li, J. Lv, G. Zhu, C. Liang, Appl. Catal. B, 2019, 241, 528-538.

[25] Z. Wang, T. Hu, K. Dai, J. Zhang, C. Liang, Chin. J. Catal., 2017, 38, 2021-2029.

[26] M. T. Mayer, C. Du, D. Wang, J. Am. Chem. Soc., 2012, 134, 12406-12409.

[27] R. van de Krol, Y. Liang, Chimia, 2013, 67, 168-171.

[28] P. Cai, S.-M. Zhou, D.-K. Ma, S.-N. Liu, W. Chen, S.-M. Huang, Nano-Micro. Lett., 2015, 7, 183-193.

[29] Y. Li, L. Zhang, R. Liu, Z. Cao, X. Sun, X. Liu, J. Luo, ChemCatChem, 2016, 8, 2765-2770.

[30] A. Verma, A. Srivastav, S. A. Khan, V. Rani Satsangi, R. Shrivastav, D. Kumar Avasthi, S. Dass, Phys. Chem. Chem. Phys., 2017, 19, 15039-15049.

[31] S. Bai, H. Chu, X. Xiang, R. Luo, J. He, A. Chen, Chem. Eng. J., 2018, 350, 148-156.

[32] W. Ma, X. Wu, K. Huang, M. Wang, R. Fu, H. Chen, S. Feng, Sustain.
Energy Fuels, 2019, 3, 2135-2141.

[33] X. Ding, Y. Gao, T. Fan, Y. Ji, L. Zhang, Z. Yu, M. S. G. Ahlquist, L. Sun, Electrochim. Acta, 2016, 215, 682-688.

[34] Y. Zhang, J. He, Q. Yang, H. Zhu, Q. Wang, Q. Xue, L. Yu, J. Power Sources, 2019, 440, 227120.

[35] A. Müller, I. Kondofersky, A. Folger, D. Fattakhova-Rohlfing, T. Bein, C. Scheu, Mater. Res. Express, 2017, 4, 016409.

[36] X. Chen, S. S. Mao, Chem. Rev., 2007, 107, 2891-2959.

[37] X. Chen, L. Liu, P. Y. Yu, S. S. Mao, Science, 2011, 331, 746-750.

[38] J. Xie, W. Liu, J. Xin, F. Lei, L. Gao, H. Qu, X. Zhang, Y. Xie, ChemSusChem, 2017, 10, 4465-4471.

[39] Q. Jiang, X. Xie, D. J. Riley, F. Xie, J. Chem. Phys., 2020, 153, 011102.

[40] A. Kay, D. A. Grave, K. Deo Malviya, D. S. Ellis, H. Dotan, A. Rothschild, J. Phys. Chem. C, 2017, 121, 28287-28292.

[41] W. W. Gärtner, Phys. Rev., 1959, 116, 84-87.

[42] Z. Wang, L. Wang, Chin. J. Catal., 2018, 39, 369-378.

[43] A. Tofanello, S. Shen, F. L. de Souza, L. Vayssieres, APL Mater., 2020, 8, 040905.

[44] J. Wang, M. Wang, T. Zhang, Z. Wang, P. Guo, J. Su, L. Guo, ACS Appl. Mater. Interfaces, 2018, 10, 12594-12602.

[45] Z. Luo, T. Wang, J. Zhang, C. Li, H. Li, J. Gong, Angew. Chem. Int. Ed., 2017, 56, 12878-12882.

[46] T. Berger, D. Monllor-Satoca, M. Jankulovska, T. Lana-Villarreal, R. Gomez, ChemPhysChem, 2012, 13, 2824-2875.

[47] T. W. Kim, K. Choi, Science, 2014, 343, 990-994.

[48] U. Bjoerksten, J. Moser, M. Graetzel, Chem. Mater., 1994, 6, 858-863.

[49] K. Sivula, R. Zboril, F. Le Formal, R. Robert, A. Weidenkaff, J. Tucek, J. Frydrych, M. Grätzel, J. Am. Chem. Soc., 2010, 132, 7436-7444.

[50] Z. Zhang, H. Nagashima, T. Tachikawa, Angew. Chem. Int. Ed., 2020, 59, 9047-9054.

[51] Z. Luo, C. Li, S. Liu, T. Wang, J. Gong, Chem. Sci., 2017, 8, 91-100.

[52] P. Kumar, P. Sharma, R. Shrivastav, S. Dass, V. R. Satsangi, Int. J. Hydrogen Energy, 2011, 36, 2777-2784.

[53] J. Deng, J. Zhong, A. Pu, D. Zhang, M. Li, X. Sun, S.-T. Lee, J. Appl. Phys., 2012, 112, 084312.

[54] Y. Ling, G. Wang, D. A. Wheeler, J. Z. Zhang, Y. Li, Nano Lett., 2011, $11,2119-2125$.

[55] C. Xiao, Z. Zhou, L. Li, S. Wu, X. Li, Nanoscale Res. Lett., 2020, 15, 54.

[56] A. Annamalai, A. Subramanian, U. Kang, H. Park, S. H. Choi, J. S. Jang, J. Phys. Chem. C, 2015, 119, 3810-3817.

[57] Y. Zhang, S. Jiang, W. Song, P. Zhou, H. Ji, W. Ma, W. Hao, C. Chen, J. Zhao, Energy Environ. Sci., 2015, 8, 1231-1236.

[58] L. Gong, J. Xie, X. Liang, J. Xiong, S. Yi, X. Zhang, C. M. Li, J. Colloid 
Interface Sci., 2019, 542, 441-450.

[59] D. Chen, Z. Liu, ChemSusChem, 2018, 11, 3438-3448.

[60] L. Li, P. Liang, C. Liu, H. Zhang, N. Mitsuzaki, Z. Chen, Int. J. Hydrogen Energy, 2019, 44, 4208-4217.

[61] A. Tofanello, A. L. M. Freitas, W. M. Carvalho, T. Salminen, T. Niemi, F. L. Souza, J. Phys. Chem. C, 2020, 124, 6171-6179.

[62] F. Li, J. Li, F. Li, L. Gao, X. Long, Y. Hu, C. Wang, S. Wei, J. Jin, J. Ma, J. Mater. Chem. A, 2018, 6, 13412-13418.

[63] R. Marschall, Adv. Funct. Mater., 2014, 24, 2421-2440.

[64] S. J. A. Moniz, S. A. Shevlin, D. J. Martin, Z.-X. Guo, J. Tang, Energy Environ. Sci., 2015, 8, 731-759.

[65] J. Leduc, Y. Gönüllü, T. P. Ruoko, T. Fischer, L. Mayrhofer, N. V. Tkachenko, C. L. Dong, A. Held, M. Moseler, S. Mathur, Adv. Funct. Mater., 2019, 29, 1905005.

[66] H. Zhang, Y. K. Kim, H. Y. Jeong, J. S. Lee, ACS Catal,, 2018, 9 $1289-1297$.

[67] M. Inaba, K. Katayama, W. Y. Sohn, Sustain. Energy Fuels, 2020, 4, 2174-2183.

[68] Y. Liang, C. S. Enache, R. van de Krol, Int. J. Photoenergy, 2008 2008, 1-7.

[69] M. R. S. Soares, C. A. R. Costa, E. M. Lanzoni, J. Bettini, C. A. O. Ramirez, F. L. Souza, E. Longo, E. R. Leite, Adv. Electro. Mater., 2019, 5, 1900065.

[70] F. Feng, C. Li, J. Jian, X. Qiao, H. Wang, L. Jia, Chem. Eng. J., 2019, 368, 959-967.

[71] P. Tang, J. Arbiol, Nanoscale Horizons, 2019, 4, 1256-1276.

[72] F. Le Formal, S. R. Pendlebury, M. Cornuz, S. D. Tilley, M. Gratzel, J. R. Durrant, J. Am. Chem. Soc., 2014, 136, 2564-2574.

[73] J. E. Thorne, S. Li, C. Du, G. Qin, D. Wang, J. Phys. Chem. Lett., 2015, 6, 4083-4088.

[74] M. G. Ahmed, I. E. Kretschmer, T. A. Kandiel, A. Y. Ahmed, F. A. Rashwan, D. W. Bahnemann, ACS Appl. Mater. Interfaces, 2015, 7, 24053-24062.

[75] C. Du, X. Yang, M. T. Mayer, H. Hoyt, J. Xie, G. McMahon, G. Bischoping, D. Wang, Angew. Chem. Int. Ed., 2013, 52, 12692-12695.

[76] F. Le Formal, N. Tétreault, M. Cornuz, T. Moehl, M. Grätzel, K. Sivula, Chem. Sci., 2011, 2, 737-743.

[77] L. Steier, I. Herraiz-Cardona, S. Gimenez, F. Fabregat-Santiago, J. Bisquert, S. D. Tilley, M. Grätzel, Adv. Funct. Mater., 2014, 24, 7681-7688.

[78] O. Zandi, T. W. Hamann, J. Phys. Chem. Lett., 2014, 5, 1522-1526.

[79] B. Klahr, S. Gimenez, F. Fabregat-Santiago, J. Bisquert, T. W. Hamann, Energy Environ. Sci., 2012, 5, 7626-7636.

[80] B. Klahr, S. Gimenez, F. Fabregat-Santiago, T. Hamann, J. Bisquert, J. Am. Chem. Soc., 2012, 134, 4294-4302.

[81] L. Bertoluzzi, L. Badia-Bou, F. Fabregat-Santiago, S. Gimenez, J. Bisquert, J. Phys. Chem. Lett., 2013, 4, 1334-1339.

[82] H. Lan, A. Wei, H. Zheng, X. Sun, J. Zhong, Nanoscale, 2018, 10, 7033-7039.
[83] Y. Yang, M. Forster, Y. Ling, G. Wang, T. Zhai, Y. Tong, A. J. Cowan, Y. Li, Angew. Chem. Int. Ed., 2016, 55, 3403-3407.

[84] J. W. Jang, C. Du, Y. Ye, Y. Lin, X. Yao, J. Thorne, E. Liu, G. McMahon, J. Zhu, A. Javey, J. Guo, D. Wang, Nat. Commun., 2015, 6, 7447.

[85] M. Barroso, C. A. Mesa, S. R. Pendlebury, A. J. Cowan, T. Hisatomi, K. Sivula, M. Gratzel, D. R. Klug, J. R. Durrant, Proc. Natl. Acad. Sci. USA, 2012, 109, 15640-15645.

[86] J. Y. Kim, J.-W. Jang, D. H. Youn, G. Magesh, J. S. Lee, Adv. Energy Mater., 2014, 4, 1400476.

[87] A. Yamaguchi, R. Inuzuka, T. Takashima, T. Hayashi, K. Hashimoto, R. Nakamura, Nat. Commun., 2014, 5, 4256.

[88] Y. Zhang, H. Zhang, A. Liu, C. Chen, W. Song, J. Zhao, J. Am. Chem. Soc., 2018, 140, 3264-3269.

[89] F. Le Formal, E. Pastor, S. D. Tilley, C. A. Mesa, S. R. Pendlebury, M. Gratzel, J. R. Durrant, J. Am. Chem. Soc., 2015, 137, 6629-6637.

[90] T. Takashima, K. Ishikawa, H. Irie, Chem. Commun., 2016, 52, 14015-14018.

[91] Y. Zhang, H. Zhang, H. Ji, W. Ma, C. Chen, J. Zhao, J. Am. Chem. Soc., 2016, 138, 2705-2711.

[92] X. Zhang, X. Wang, X. Yi, J. Ye, D. Wang, ACS Sustain. Chem. Eng., 2019, 7, 5420-5429.

[93] W. Li, D. He, S. W. Sheehan, Y. He, J. E. Thorne, X. Yao, G. W. Brudvig, D. Wang, Energy Environ. Sci., 2016, 9, 1794-1802.

[94] L. M. Peter, J. Solid State Electrochem., 2012, 17, 315-326.

[95] D. K. Zhong, D. R. Gamelin, J. Am. Chem. Soc., 2010, 132, 4202-4207.

[96] J. Xiao, L. Fan, Z. Huang, J. Zhong, F. Zhao, K. Xu, S.-F. Zhou, G. Zhan, Chin. J. Catal., 2020, 41, 1761-1771.

[97] F. Li, Z. Zhao, H. Yang, D. Zhou, Y. Zhao, Y. Li, W. Li, X. Wu, P. Zhang, L. Sun, Dalton Trans., 2020, 49, 588-592.

[98] J. Y. Kim, D. H. Youn, K. Kang, J. S. Lee, Angew. Chem. Int. Ed., 2016, 55, 10854-10858.

[99] G. Wang, B. Wang, C. Su, D. Li, L. Zhang, R. Chong, Z. Chang, J. Catal., 2018, 359, 287-295.

[100] C. Wang, X. Long, S. Wei, T. Wang, F. Li, L. Gao, Y. Hu, S. Li, J. Jin, ACS Appl. Mater. Interfaces, 2019, 11, 29799-29806.

[101] A. Y. Ahmed, M. G. Ahmed, T. A. Kandiel, J. Phys. Chem. C, 2016, 120, 23415-23420.

[102] L. Wang, K. Fan, H. Chen, Q. Daniel, B. Philippe, H. Rensmo, L. Sun, Catal. Today, 2017, 290, 73-77.

[103] K. Fan, F. Li, L. Wang, Q. Daniel, H. Chen, E. Gabrielsson, J. Sun, L. Sun, ChemSusChem, 2015, 8, 3242-3247.

[104] T. Hisatomi, H. Dotan, M. Stefik, K. Sivula, A. Rothschild, M. Gratzel, N. Mathews, Adv. Mater., 2012, 24, 2699-2702.

[105] F. Bouhjar, B. Bessaïs, B. Marí, J. Solid State Electrochem., 2018, 22, 2347-2356.

[106] D. Cao, W. Luo, J. Feng, X. Zhao, Z. Li, Z. Zou, Energy Environ. Sci,, 2014, 7, 752-759.

[107] T. H. Jeon, G.-H. Moon, H. Park, W. Choi, Nano Energy, 2017, 39, 211-218.

\title{
提高氧化铁光电催化分解水效率的策略进展
}

\author{
周定华，范 科* \\ 大连理工大学-瑞典皇家工学院分子器件联合研究中心, 能源研究院, 辽宁大连 116024
}

摘要: 为了解决能源危机与环境污染问题, 发展一种可再生的清洁能源至关重要. 太阳能是一种取之不尽用之不竭的清洁 能源, 而氢气是一种良好的能源载体. 利用太阳能光电催化水分解制氢, 是一项有望能够解决能源与环境问题的技术, 具 有很大的应用前景. 其中, 氧化铁因为具有合适的能带位置与带隙、良好的稳定性与廉价无毒等优点, 成为一种理想的光 
阳极材料. 但是, 在实际的测试中, 氧化铁仅仅只能得到一个较低的光电转换效率, 这可能是因为其较短的空穴扩散距离、 较低的电导率以及极度缓慢的水氧化反应动力学所致.

整个光电催化水氧化可分为三个过程, 即光吸收过程、电荷分离过程以及表面空穴注入过程. 这三个过程的效率共同 决定了器件的太阳能转化效率. 鉴于此, 本文将从如何提高这三个效率的角度出发, 总结近期研究报道中提高氧化铁光电 催化分解水效率的一些策略.

光吸收过程是指半导体中价带的电子在吸收具有一定能量的光子后发生跃迁, 产生空穴-电子对的过程. 其光子的损 失主要来源于光的反射、透射以及半导体吸收边的限制. 提高光吸收效率的主要策略包括制备具有特定纳米结构的氧化 铁电极、利用表面等离子体共振效应以及组成双光吸收系统和掺杂等.

电荷分离过程指的是受光激发产生的空穴电子对, 在内建电场的作用下发生电荷分离, 即光生空穴流向电极表面, 光 生电子流向半导体内部并从外电路导出. 电荷分离效率的损失主要来源于光生载流子在迁移过程中的复合. 因此, 为了提 高电荷分离效率, 常见的策略是提高载流子在电荷分离过程中的复合时间 $\tau_{1}$ 和减少电荷迁移到表面(空穴)或者基底(电子) 的时间 $\tau_{2}$. 具体的策略包括制备特定的纳米结构(缩短体表相距离, 减少 $\tau_{2}$ )、构建异质结(增强能带弯曲, 提高 $\tau_{1}$ 和减少 $\tau_{2}$ )、 掺杂(减少 $\left.\tau_{2}\right)$ 和钝化复合中心(提高 $\tau_{1}$ ) 等.

表面空穴注入是指到达表面的光生空穴发生水氧化反应生成氧气的过程. 除了空穴注入外, 表面还可能存在复合与 逆反应过程. 因此, 为了提高表面空穴注入效率, 我们既可以提高水氧化反应动力学, 具体的手段包括引入水氧化催化剂、 $\mathrm{F}$ 掺杂和碱处理等; 也可以采用减少复合反应的策略, 具体的方法包括引入钝化层、酸处理和高温热处理等; 还可以采用减 少逆反应的方法, 最常见的手段就是在基底与氧化铁层之间引入电子阻挡层. 上述三种途径都能提高表面空穴注入效率.

最后, 通过结合上述的一些策略, 目前得到的最高性能的氧化铁电极在 $1.23 \mathrm{~V}$ (相对于可逆氢电极)能够达到 $6 \mathrm{~mA} \mathrm{~cm}$ 的光电催化分解水电流, 但这个值依然明显低于氧化铁的理论值 $(12.6 \mathrm{~mA} \mathrm{~cm}$ ). 这可能是由于体相复合所致. 除此之外, 氧化铁表面的水氧化机理现在依然不清晰, 这些都是需要我们在未来解决的问题.

关键词: 氧化铁; 光吸收效率; 电荷分离效率; 表面空穴注入效率

收稿日期: 2020-08-08. 接受日期: 2020-09-21. 上网日期: 2020-11-22.

*通讯联系人. 电子信箱: kefan@kth.se

基金来源：国家自然科学基金(51772234); 大连理工大学(DUT19RC(3)063).

本文的电子版全文由Elsevier出版社在ScienceDirect上出版(http://www.sciencedirect.com/science/journal/18722067). 